\title{
Education during COVID-19 Lockdown and Social Distancing: Programmable Teaching Aid for Amplitude Modulation Theory as a Case Study
}

\author{
Abdul Rasak Zubair \\ Electrical/Electronic Engineering Department \\ University of Ibadan, \\ Ibadan, Nigeria
}

\author{
Sulaiman Seun Folorunsho \\ Department of Early Childhood Care and Education, \\ Federal College of Education, Yola, Nigeria \\ PhD Program: Department of Early Childhood Care \\ and Educational Foundations, \\ University of Ibadan, \\ Ibadan, Nigeria
}

\begin{abstract}
The novel Coronavirus is a strain of severe acute respiratory syndrome (SARS). COronaVIrus Disease 2019 (COVID-19) was previously referred to as the 2019-novel Coronavirus (2019-nCoV). It originated from Wuhan, a city in China. It spread very fast and became a pandemic. Measures adopted to halt the spread of the virus include lockdown, social distancing, self-isolation, and quarantine. During the lockdown, people are told to stay at home or work from home. Many countries closed their schools and educational institutions. Universities postponed or cancelled lectures, workshops, seminars, conferences, and sports activities. Institutions are transferring various courses and programs from face-to-face in physical class to online delivery mode in a virtual class. There is a need for special teaching aids to compensate for the lack of physical closeness between the lecturer and the students. The development of a user-friendly Programmable Teaching Aid for Amplitude Modulation Theory (ProgT-Aid_AM) is presented as a case study. With ProgT-Aid_AM, students can generate six illustrative Graphs and can perform experiments on their own at their save locations to enable them to appreciate the basic concepts of the subject. Computations of the modulation index, peak-to-peak value, and power-saving are demonstrated. Development of such programmable teaching aid in all fields of learning is recommended to stimulate students' interest, to enable students' centered teaching, to make teaching/learning at a distance effective, and to reduce the adverse effect of COVID-19 lockdown and social distancing on education.
\end{abstract}

\section{General Terms}

COVID-19, Telecommunication, Algorithm Development

\section{Keywords}

COVID-19, Lockdown, Social distancing, Education, Teaching Aid, Amplitude Modulation, modulation index

\section{INTRODUCTION}

The novel Coronavirus caught the world unaware. Both the developing world and the developed world were not adequately prepared for the devastating effects of the virus, which practically collapsed the social and interactivity interplay of man. The novel Coronavirus is a strain of the severe acute respiratory syndrome (SARS), it originated in Wuhan, China, and is primarily a respiratory disease [1]. The COronaVIrus Disease 2019 (COVID-19) arguably originated from the Chinese city of Wuhan, towards the end of 2019 [2],
[3]. It is majorly a respiratory disease and it is spread primarily through droplets of infected individuals falling into the respiratory tract of a healthy person through the mouth and nose. Coronavirus Disease 2019 (COVID-19) was previously referred to as the 2019-novel Coronavirus (2019-nCoV) [3], [4].

COVID-19 spreads very fast, it started at the end of the year 2019. By the end of the first quarter 2020, precisely 29th march, 2020, the virus had spread to 177 countries representing almost 90 percent prevalence in terms of countries with infections, and the number of infected individuals had risen to close to a million individuals [2], [4], [5], [6], [7], [8].

In most countries that have recorded infections, public health experts and government officials are taking several measures, including lockdown, social distancing, self-isolation, and quarantine. People are/were told to stay at home or work from home among other measures to ensure the halt of the spread of the virus [5], [9], [10], [11]. Sahu (2020) further asserted that places with large gatherings, inclusive of educational institutions around the world had been ordered close to fight this invisible enemy called COVID-19 [2]. As of March 25, 150 countries had closed schools and educational institutions nationally, impacting over $80 \%$ of the world's student population.

Primary Schools, Secondary Schools, Colleges of Education, Polytechnics, and Universities are also closed in Nigeria to stop the spread of COVID-19 [12], [13]. The Coronavirus has affected all facets of life and has devastated the human race in many ways. The adverse effects of the virus on education include the disruption of the Academic Calendar of Higher Institutions. The Federal Government of Nigeria ordered the immediate closure of all institutions on March 19, 2020 [12], [13], [14].

In the light of rising concern about the COVID-19 pandemic, a growing number of universities across the world have either postponed or cancelled all campus events such as lectures, workshops, seminars, conferences, sports, and other activities [15], [16], 17]. Universities have moved rapidly to transfer various courses and programs from face-to-face to online delivery mode [18], [19].

The incorporation of online mode of delivery is greatly enhanced by the ability to migrate successfully from a physical arrangement, slowly but systematically to an 
online-based or mixed-method of instruction or at least a system that relies more on learner-centered approaches to teaching. Development and deployment of appropriate teaching aids are necessary for virtual class teaching and learning.

Nevertheless, there is always a chance that some faculties that are not technologically inclined may not be able to cope with the online-mode of teaching. The shift from physical class to virtual class has become necessary to curb the spread of COVID-19 [19], [20].

Researchers have over the years also noted that the inability to properly assess students through online means is a very great shortcoming of the virtual surrogate learning [21]. This implies that any attempt to develop computer-assisted instruction should also consider developing a suitable adequate online assessment. This opinion is more glaring in situations where the curriculum and indeed whole educational system is developed without the significant consideration of switching to the virtual class mode or even the adoption of the more teacher-friendly, technological driven means of delivering lectures.

The Nigerian educational system is modeled and designed to cater for face to face physical class situation. The reality, however, points to the fact that we may need to live with and adjust our way of life including our educational system to suite the existence of the Coronavirus pandemic. This then calls for the exploitation of modern technology and information communication technology in teaching and learning especially in higher education [22]. Tele-teaching or Tele-lecturing means teaching or lecturing at a distance. There is a distance between the Lecturer and the students. The lecturer and the students are in several different geographical locations. There is a need for special teaching aids to compensate for the lack of physical closeness between the lecturer and the students. The lecturer needs to find suitable means and ways to explain the basic concepts of the subject matter to the students efficiently, such that both the lecturer and students consume fewer internet data. The cost of internet data is an issue in developing countries.

Teaching is an art. Teaching includes dissemination and presentation of knowledge. The Teacher must have a broad knowledge of the subject matter. The Teacher must be caring and enthusiastic. The Teacher is eager that the students assimilate the basic concepts and that the student attains a full understanding of the subject matter [23]. The Teacher develops and uses teaching aids to enhance teaching [24], [25]. Teaching aids enable students to participate actively in learning. Active participation enables the students to grasp and internalize the fundamental concepts of the subject matter. Teaching aid relieves anxiety or boredom or monotony by presenting information and concepts in new and exciting ways, thereby promoting sensory engagement and stimulation.

As the class migrates from a physical arrangement to a virtual arrangement, teaching aids also need to be made available online. Computer generation of teaching aids becomes necessary. In this work, a Programmable Teaching Aid (ProgT-Aid_AM) for amplitude modulation theory is presented as a case study. Amplitude modulation is a key aspect of electronic communication (telecommunication) in Electrical and Electronic Engineering. A computer program or an algorithm is a systematic logical procedure for solving a problem [26].

\section{AMPLITUDE MODULATION}

\subsection{Electronic Communication}

Telecommunication class or Electronic communication class often begins with the history of communication. Students are made to research how his/her indigenous community communicated in ancient times before the advent of electronic communication. In most African countries, there were local and traditional communication systems such as the concept of town crier and smoke [27], [28], [29]. Messengers trek long distances carrying information from one person to another. In Yoruba land in Western Nigeria, the use of "Àrokò" was a popular symbol-communication system in the olden days. Àrokò is a symbol-object or collection of symbol-objects assembled as a parcel and sent through a messenger to convey information to be decoded by the receiver [30]. The objects were used as codes that can be decoded to obtain the actual message or messages.

Communication is the exchange of useful information between two or more parties. The useful information is encoded in words or other symbols, the code is sent to the receiver; and the code is decoded or interpreted to extract the information at the receiving end [29].

Electronic communication is the transfer of information from one point to another by electronic means. Information or intelligence or signal is anything that has some meaning. Examples of such information include written words, speech, music, image, video, temperature, and humidity just to mention a few. Anything which has no meaning or sense is called "Noise" [31], [32]. Students are made to understand the advantages of electronic communication systems over ancient communication systems; these include higher speed, longer range, user-friendliness, and privacy. Information now travels at the speed of light and the world has now become a global village. The students are introduced to early electronic communication systems such as Telegraphy and the Morse code [32].

The students are exposed to the components of the electronic communication system. Fig. 1 shows the block diagram of a typical electronic communication system. The Source is the origin of information which can be in any form; the Source can be man or machine. The Input Transducer converts the information from its form at origin to an electronic signal. Microphone, Digital Camera, and Keyboard are examples of Input Transducers. Four important processes take place in the Transmitter; namely Amplification, Filtering, Modulation, and Coupling to the Channel. The Channel is the medium through which the information passes. The Channel can be space or wires.

The Receiver receives the information from the Channel and also carries out the processes of Amplification, Filtering, and Demodulation. The Output Transducer converts the information from an electronic signal to a form desired at the Destination. Speaker and TV Monitor are examples of Output Transducers. The Destination or the Sink is the end-user or recipient of the information; it can also be man or machine.

The Noise is an unwanted signal tending to interfere with or obscure the desired signal. The Noise is symbolically presented as entering the system via the Channel but students are made to understand that the Noise does enter the system via all the components of the system. The students study all the components and subcomponents of the system gradually [31], [32]. 


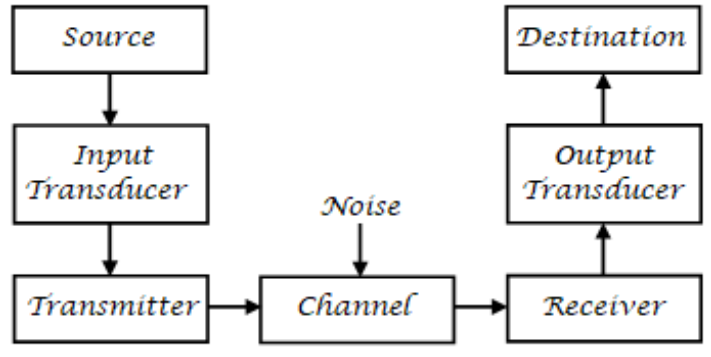

Fig 1: Block Diagram of a typical electronic communication system

The information is converted to an electronic signal by the Input Transducer. This electronic signal is called informationbearing signal or baseband signal. The frequency of this information-bearing signal is often in the lower frequency range. For this low frequency signal to travel long distance as an electromagnetic wave, it must be carried by another signal of higher frequency. This other signal is called the "Carrier". The process is known as Modulation and the informationbearing signal is also called the "Modulating signal". Modulation is the translation of an information-bearing signal to a higher frequency and it takes place in the Transmitter [31], [32].

The second reason for modulation is to allow for multiplexing [31], [32]. Multiplexing is the transmission of two or more different information-bearing signals over the same channel without interference. Modulation can be classified into Analog Modulation or Digital Modulation. Analog Modulation includes Amplitude Modulation (AM), Frequency Modulation (FM), and Phase Modulation (PM).

\subsection{Amplitude Modulation Theory}

Amplitude Modulation is the systematic variation of the amplitude of the Carrier in accordance with the instantaneous amplitude of the information-bearing signal or Modulating signal [31], [32], [33], [34], [35]. Suppose the instantaneous amplitudes of the Modulating signal and the Carrier are $\mathrm{v}_{\mathrm{m}}$ and $v_{c}$, respectively which are given by Eqns. (1) and (2), respectively. Suppose $v_{a m}$ is the instantaneous amplitude of the Amplitude Modulated wave. According to the definition of amplitude modulation, the instantaneous amplitude of the Amplitude Modulated Wave is given by Eqn. (3) [31], [32], [33], [34], [35]. Amplitude Modulation System is a two-inputs-one-output system as illustrated in Fig. 2.

$$
\begin{gathered}
v_{m}(t)=A_{m} \operatorname{Cos}\left(2 \pi f_{m} t\right) \\
v_{c}(t)=A_{c} \operatorname{Cos}\left(2 \pi f_{c} t\right)
\end{gathered}
$$

where $A_{m}$ and $A_{c}$ are the maximum amplitudes of the Modulating signal and the Carrier, respectively; $f_{m}$ and $f_{c}$ are the frequencies of the Modulating signal and the Carrier, respectively. $f_{c}$ is expected to be greater than $f_{m}$ to fulfill the purpose of modulation.

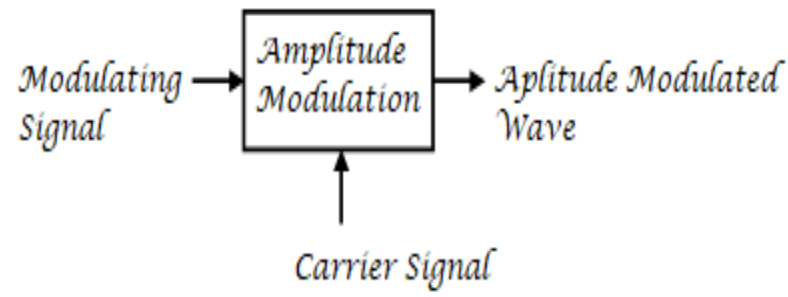

Fig 2: Amplitude Modulation Process $v_{a m}(t)=\left[A_{c}+A_{m} \operatorname{Cos}\left(2 \pi f_{m} t\right)\right] \operatorname{Cos}\left(2 \pi f_{c} t\right)$

(3)

Eqn. (3) can be written as

$$
\begin{aligned}
v_{a m}(t)= & A_{c} \operatorname{Cos}\left(2 \pi f_{c} t\right) \\
& +A_{m} \operatorname{Cos}\left(2 \pi f_{m} t\right) \operatorname{Cos}\left(2 \pi f_{c} t\right)
\end{aligned}
$$

Using $\operatorname{Cos}(P+Q)=\operatorname{Cos} P \operatorname{Cos} Q-\operatorname{Sin} P \operatorname{Sin} Q$ and

$$
\begin{aligned}
\operatorname{Cos}(P-Q)= & \operatorname{Cos} P \operatorname{Cos} Q+\operatorname{Sin} P \operatorname{Sin} Q \text { gives } \\
v_{a m}(t)= & A_{c} \operatorname{Cos}\left(2 \pi f_{c} t\right) \\
& +\frac{A_{m}}{2} \operatorname{Cos}\left[2 \pi\left(f_{c}-f_{m}\right) t\right] \\
& +\frac{A_{m}}{2} \operatorname{Cos}\left[2 \pi\left(f_{c}+f_{m}\right) t\right]
\end{aligned}
$$

Amplitude modulation index $\mathrm{m}$ is defined as the ratio of the maximum amplitude of the Modulating signal to the maximum amplitude of the Carrier. $m$ is given by Eqn. (6). Substitution of $A_{m}$ in Eqn. (5) using Eqn. (6) gives Eqn. (7).

$$
\begin{gathered}
m=\frac{A_{m}}{A_{c}} \\
v_{a m}(t)=A_{c} \operatorname{Cos}\left(2 \pi f_{c} t\right) \\
+\frac{m}{2} A_{c} \operatorname{Cos}\left[2 \pi\left(f_{c}-f_{m}\right) t\right] \\
+\frac{m}{2} A_{c} \operatorname{Cos}\left[2 \pi\left(f_{c}+f_{m}\right) t\right]
\end{gathered}
$$

(7)

Eqn. (7) shows that the Amplitude Modulated wave has three frequency components which are $\mathrm{f}_{c}, \mathrm{f}_{\mathrm{c}}+\mathrm{f}_{\mathrm{m}}$, and $\mathrm{f}_{\mathrm{c}}-\mathrm{f}_{\mathrm{m}}$. Eqns. (1), (2) and (5) describe the three signals $\left(\mathrm{v}_{\mathrm{m}}, \mathrm{v}_{\mathrm{c}}\right.$, and $\mathrm{v}_{\mathrm{am}}$, respectively) mathematically. Students also need to know and visualize the Frequency Spectra and Waveforms of these three signals.

\subsection{Frequency Spectra of AM Signals}

The Frequency Spectrum of a signal is the range of frequencies contained by a signal; it's a plot of maximum amplitude against the frequency. Fig. 3 (a), (b), and (c) show the Frequency Spectra of the Modulating signal, the Carrier signal, and the Amplitude Modulated wave, respectively. The Carrier signal usually has one component at $\mathrm{f}_{\mathrm{c}}$ as illustrated in Fig. 3(b). The Modulating signal can have one or more component(s). If the modulating signal has a single component at $f_{m}$ as shown in Fig. 3(a), the Amplitude Modulated wave has three frequency components at $\mathrm{f}_{\mathrm{c}}, \mathrm{f}_{\mathrm{c}}+\mathrm{f}_{\mathrm{m}}$, and $f_{c}-f_{m}$ as illustrated in Fig. $3(c) . f_{c}+f_{m}$ is known as the Upper Side Frequency and $\mathrm{f}_{\mathrm{c}}-\mathrm{f}_{\mathrm{m}}$ is known as the Lower Side Frequency. Full AM of Eqn. (7) contains the Carrier frequency component, the Lower Side Frequency component, and the Upper Side Frequency component.

If a Modulating signal with three frequency components at $\mathrm{f}_{1}$, $\mathrm{f}_{2}$, and $\mathrm{f}_{3}$ is used to modulate a Carrier signal with a single frequency component at $f_{c}$, the Amplitude Modulated wave will contain seven frequency components at $f_{c}, f_{c}-f_{1}, f_{c}-f_{2}$, $\mathrm{f}_{\mathrm{c}}-\mathrm{f}_{3}, \mathrm{f}_{\mathrm{c}}+\mathrm{f}_{1}, \mathrm{f}_{\mathrm{c}}+\mathrm{f}_{2}$, and $\mathrm{f}_{\mathrm{c}}+\mathrm{f}_{\mathrm{m}}$ as illustrated in Fig. $4 . \mathrm{f}_{\mathrm{c}}+\mathrm{f}_{1}, \mathrm{f}_{\mathrm{c}}+\mathrm{f}_{2}$, and $f_{c}+f_{m}$ constitute the Upper Side Band (USB) while $f_{c}-f_{1}$, 
$\mathrm{f}_{\mathrm{c}}-\mathrm{f}_{2}$, and $\mathrm{f}_{\mathrm{c}}-\mathrm{f}_{3}$ constitute the Lower Side Band (LSB). Full AM contains the Carrier frequency component, the Lower Side Band (LSB), and the Upper Side Band (USB).

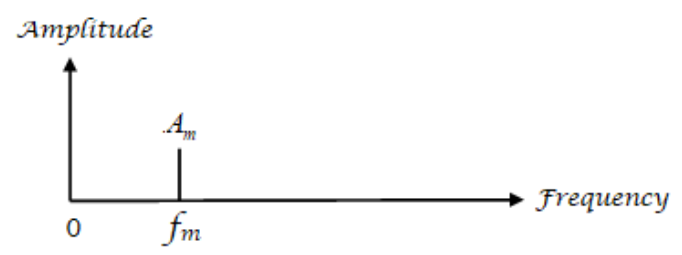

(a) Frequency Spectrum of the Modulating Signal

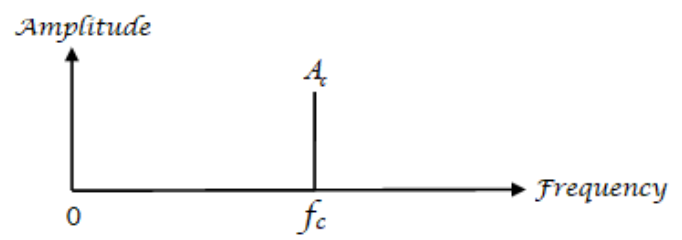

(b) Frequency Spectrum of the Carrier Signal

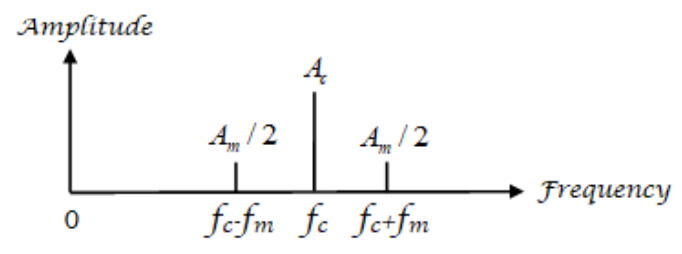

(c) Frequency Spectrum of the Amplitude Modulated Wave
Full AM is said to waste both power and bandwidth. The Carrier contains no information. Transmission of the Carrier frequency component in the Full AM is a waste of power. Double Sideband Suppressed Carrier (DSBSC) is a version of the full AM but with the Carrier frequency component suppressed before transmission as described by Eqn. (8). DSBSC saves power. The two side bands, USB and LSB, carry the same information. The transmission of both bands is a waste of bandwidth. Single Side Band (SSB) is a version of the Full AM with the Carrier frequency component and a side band suppressed before transmission as described by Eqn. (9) or Eqn. (10). SSB saves both power and bandwidth [31], [32] Sending both side bands as in Full AM and DSBSC is duplication but it has an advantage; if a band suffered attenuation or degradation due to noise or interference in the transmission medium (channel), the other band may be recovered correctly.

$$
\begin{aligned}
v_{D S B S C}(t)= & \frac{m}{2} A_{c} \operatorname{Cos}\left[2 \pi\left(f_{c}-f_{m}\right) t\right] \\
& +\frac{m}{2} A_{c} \operatorname{Cos}\left[2 \pi\left(f_{c}+f_{m}\right) t\right] \\
v_{S S B}(t)= & \frac{m}{2} A_{c} \operatorname{Cos}\left[2 \pi\left(f_{c}-f_{m}\right) t\right] \\
v_{S S B}(t)= & \frac{m}{2} A_{c} \operatorname{Cos}\left[2 \pi\left(f_{c}+f_{m}\right) t\right]
\end{aligned}
$$

Fig 3: Frequency Spectra of AM waves with the modulating signal having only one frequency component

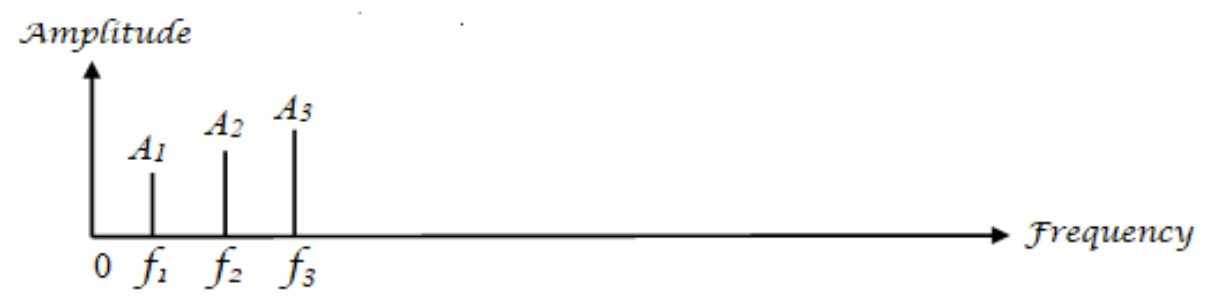

(a) Frequency Spectrum of the Modulating Signal

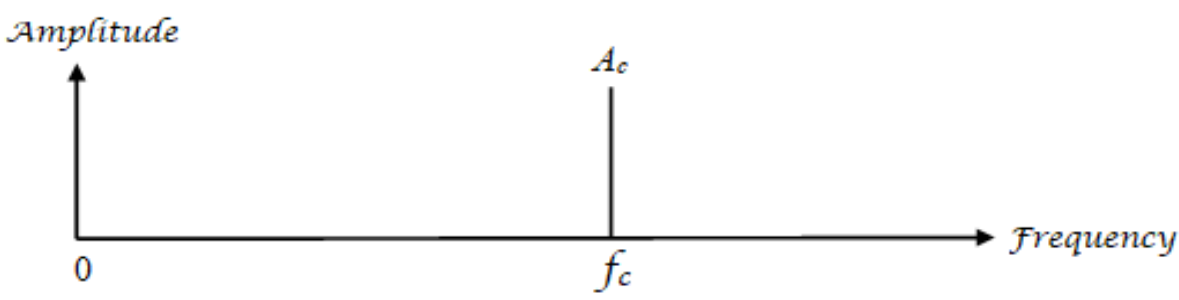

(b) Frequency Spectrum of the Carrier Signal

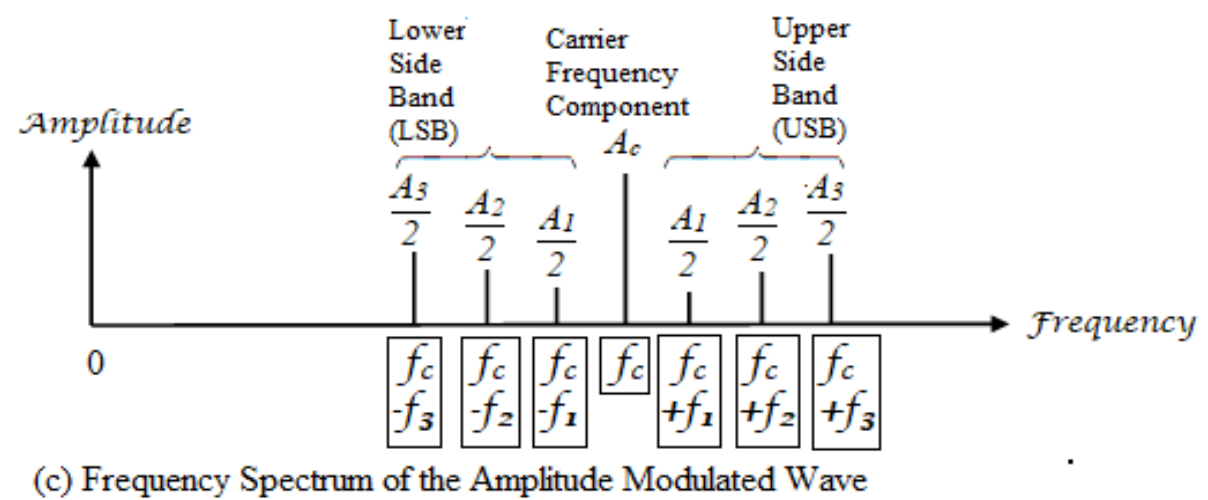

Fig 4: Frequency Spectra of AM waves with the modulating signal having three frequency components 
Power in a current or voltage signal is the root mean square value of the signal raised to power 2 ; the resistance is assumed to be $1 \Omega$. The root mean square value of the signal is the maximum value of the signal divide by $\sqrt{2}$. Let $P_{c}$, $\mathrm{P}_{\mathrm{LSB}}$, and $\mathrm{P}_{\mathrm{USB}}$ be the power in the Carrier frequency component, LSB, and USB, respectively. Let $\mathrm{P}_{\mathrm{SB}}$ be the power in the two side bands and let $\mathrm{P}_{\mathrm{AM}}$ be the total power in the Full AM of Eqn. (7). Based on Eqns. (7) to (10), $P_{c}, P_{L S B}$, $\mathrm{P}_{\mathrm{USB}}, \mathrm{P}_{\mathrm{SB}}$, and $\mathrm{P}_{\mathrm{AM}}$ are given by Eqns. (11), (12), (13), (14), and (15), respectively.

$$
\begin{gathered}
P_{c}=\left(\frac{A_{c}}{\sqrt{2}}\right)^{2}=\frac{A_{c}{ }^{2}}{2} \\
P_{L S B}=\left(\frac{m A_{c} / 2}{\sqrt{2}}\right)^{2}=\frac{m^{2} A_{c}{ }^{2}}{8} \\
P_{U S B}=\left(\frac{m A_{c} / 2}{\sqrt{2}}\right)^{2}=\frac{m^{2} A_{c}^{2}}{8} \\
P_{S B}=2 P_{U S B}=\frac{m^{2} A_{c}^{2}}{4} \\
P_{A M}=P_{c}+P_{L S B}+P_{U S B} \\
=\frac{A_{c}^{2}}{2}+\frac{m^{2} A_{c}^{2}}{4}=\frac{\left(2+m^{2}\right) A_{c}^{2}}{4}
\end{gathered}
$$

The percentage power-saving by DSBSC is given as

$$
\begin{aligned}
\text { Psaving }_{D S B S C} & =\frac{100\left(P_{A M}-P_{S B}\right)}{P_{A M}} \% \\
& =\frac{100\left(P_{c}\right)}{P_{A M}} \%=\frac{200}{2+m^{2}} \%
\end{aligned}
$$

The Eqns. (1) to (18) are the mathematical descriptions of Amplitude Modulation and are the bedrock of the Amplitude Modulation theory. Figs. 1 to 4 are teaching aids that can easily be drawn with Microsoft word.

\subsection{Waveforms of AM Signals}

The waveform of a signal is the graphical representation of the signal; it's a plot of the instantaneous amplitude of the signal against time. It's easier to sketch the frequency Spectra than the waveforms of the signals. The waveforms contain more information that would enable the students to grasp the basic concepts.

Modulation takes place at the transmitter. The Carrier in modulation is simply used to carry the Modulating signal (information bearing signal) across the channel to the receiver. Demodulation is required at the receiver to undo the modulation and recover the modulating signal. If a letter is enveloped by the sender, the recipient must first de-envelope the letter before gaining access to the content. That is the similitude for modulation and demodulation. The basis for demodulation is visible from the waveform of the Amplitude Modulated wave.

\subsection{Programmable Teaching Aid for Amplitude Modulation}

In a physical class, the lecturer can draw these waveforms on the board and explain it to the students. This is not possible for a virtual class. An algorithm in the form of a computer program was therefore developed to plot the waveforms of the Modulating Signal, the Carrier Signal, the Amplitude Modulated wave, the Amplitude Demodulated wave, Double Side Band Suppressed Carrier (DSBS) wave, and Single Side Band (SSB) wave. The waveform of the Amplitude Modulated wave has a wide peak-to-peak value $\mathrm{A}$ and a narrow peak-to-peak value $\mathrm{B}$. $\mathrm{A}$ and $\mathrm{B}$ are related to $\mathrm{A}_{\mathrm{m}}$ and $A_{c}$ as described by Eqns. (19) and (20), respectively.

$$
\begin{aligned}
& A=2 A_{c}+2 A_{m} \\
& B=2 A_{c}-2 A_{m}
\end{aligned}
$$

Eqn. (19) plus Eqn. (20) gives

$$
A+B=4 A_{c}
$$

Eqn. (19) minus Eqn. (20) gives

$$
A-B=4 A_{m}
$$

Therefore, another version of Eqn. (6) is

$$
m=\frac{A_{m}}{A_{c}}=\frac{(A-B) / 4}{(A+B) / 4}
$$

Therefore,

$$
m=\frac{A-B}{A+B}
$$

The program also calculates and displays the modulation index using both Eqn. (6) and Eqn. (24). Furthermore, the program computes the power-savings of DSBSC and SSB.

MATLAB has numerous facilities for handling arithmetic operations, logical operations, repetitive operations, decision making, and plotting graphs. Text, Labels, and titles can be added to specified locations on graphs. Sub-graphs can be made on the same graph. Different colors and designs can be programmed [26], [36], [37], [38], [39], [40].

The graphs of the Modulating Signal, the Carrier Signal, the Amplitude Modulated wave, the Double Side Band suppressed Carrier (DSBS) wave, and the Single Side Band (SSB) wave were based on Eqns. (1), (2), (3), (8), and (9), respectively. Eqn. (4) or (5) or (7) can also be used for the Amplitude Modulated wave. Eqn. (10) can also be used for the Single Side Band (SSB) wave. The computation of the modulation index $\mathrm{m}$ was based on Eqns. (6) and (24). The computation of Power-saving by the Double Side Band Suppressed Carrier (DSBSC) and the Single Side Band (SSB) 
were based on Eqn. (16) and (17), respectively.

The Programmable Teaching Aid for Amplitude Modulation Theory (ProgT-Aid_AM) is presented in the Appendix. It's simple to run, user friendly, and can be made available to students. The students can generate the waveforms in their respective safe locations.

$\mathrm{A}_{\mathrm{c}}$ is fixed at $2 \mathrm{~V}$ or $\mathrm{A}$. Students themselves on their own and in their safe locations can experiment individually on the effect of variation of $A_{m}$ by varying $A_{m}$ from 0 to 4 . Each student can see the consequence if the modulation index is greater than 1 . The students should take note of the following instructions in color green which are included in the program as presented in the Appendix. Students should read at least the first twenty lines of the program for instructions and information. The program outputs six graphs labelled Graph 1 to Graph 6.

$\%$ Set the value of the maximum amplitude Am of the
Modulating signal.

$\%$ Choose any value between 0 to 4 . Replace the value next line.

$\mathrm{Am}=1$;

$\%$ change $\mathrm{Am}=1$; above to $\mathrm{Am}=\mathrm{x}$; where $\mathrm{x}$ is between 0 and 4.

$\%$ Re-save the program and run the program.

\section{RESULTS AND DISCUSSIONS}

ProgT-Aid_AM was tested with different values of $A_{m}$, the maximum amplitude of the Modulating Signal. The results are presented and discussed in this section.

\subsection{Modulation index less or equal to 1}

$A_{m}$ is set equal to $1 ; m=0.5$. The six graphs generated are presented in Figs. 5 to 10. Graph 1 (Fig. 5) shows the waveforms of the Modulating Signal, the Carrier Signal, the Amplitude Modulated wave, and the Demodulated wave together on the same graph sheet.

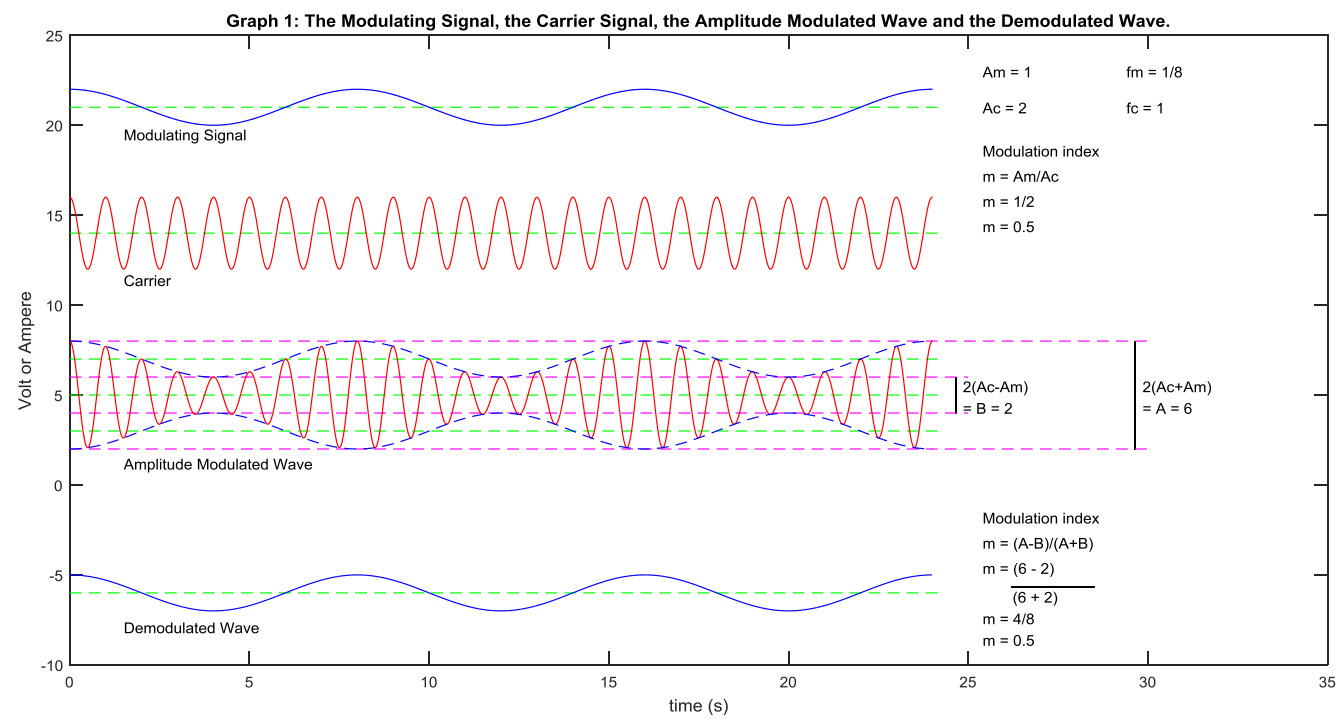

Fig 5: Graph 1 for $A_{m}=1 ; m=0.5$.

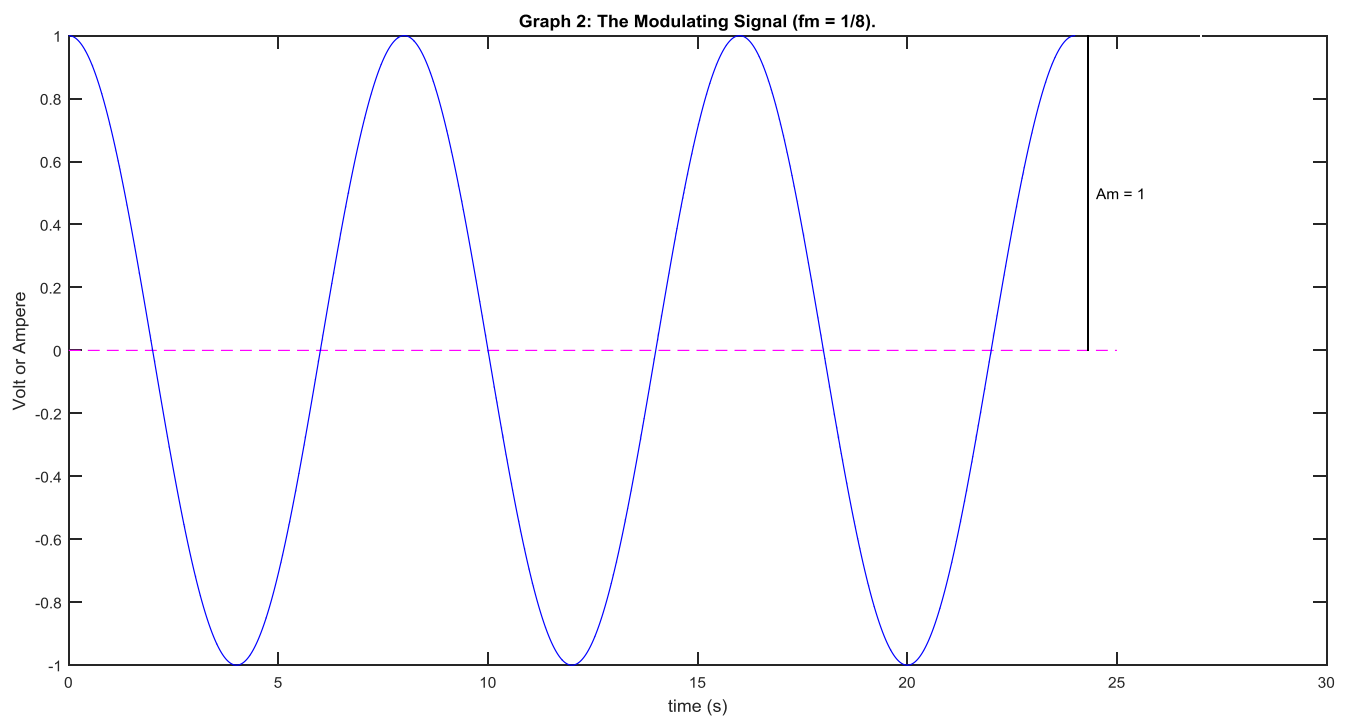

Fig 6: Graph 2 for $A_{m}=1 ; m=0.5$. 


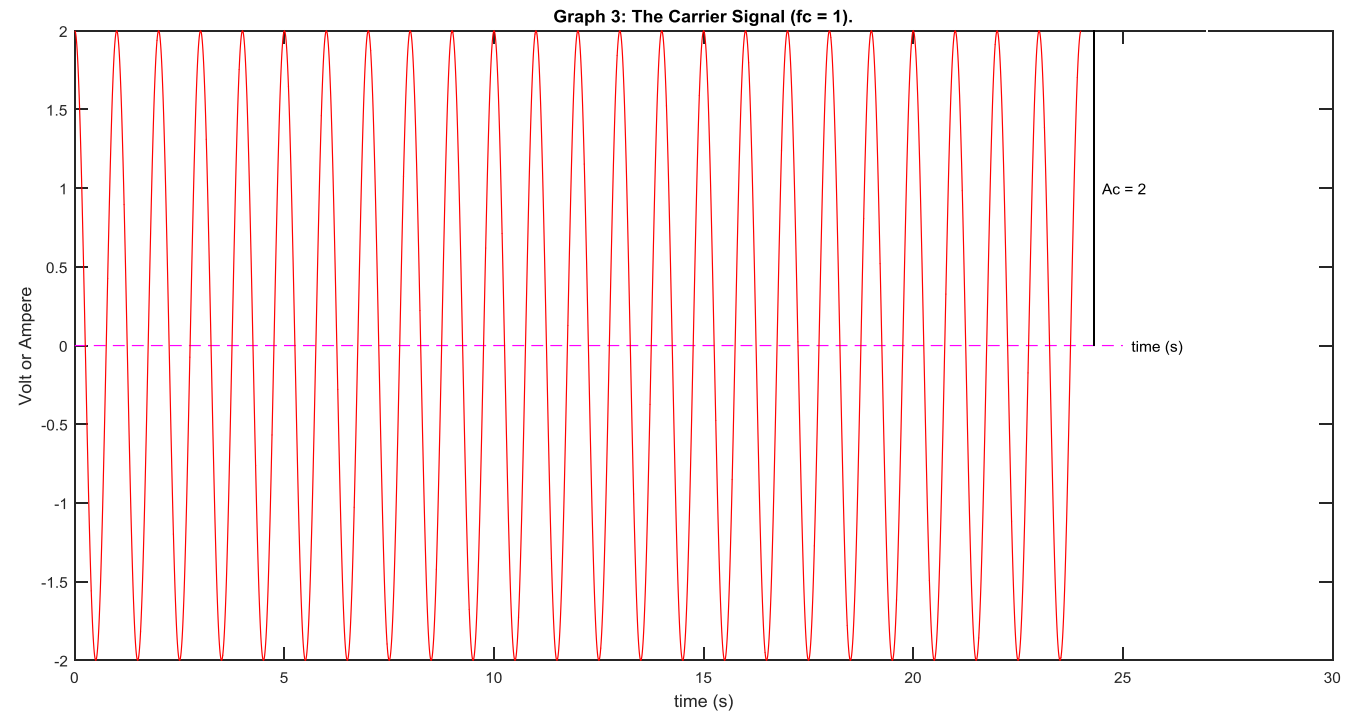

Fig 7: Graph 3 for $A_{m}=1 ; m=0.5$.

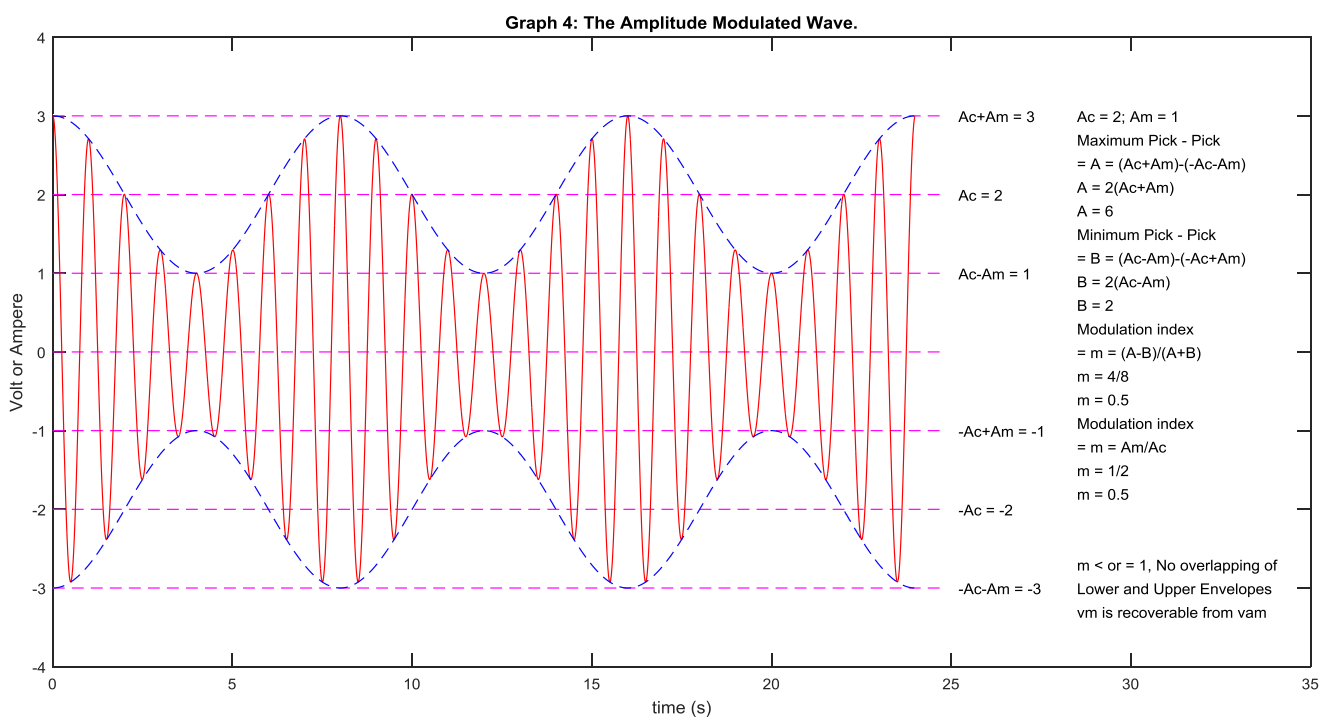

Fig 8: Graph 4 for $A_{m}=1 ; m=0.5$.

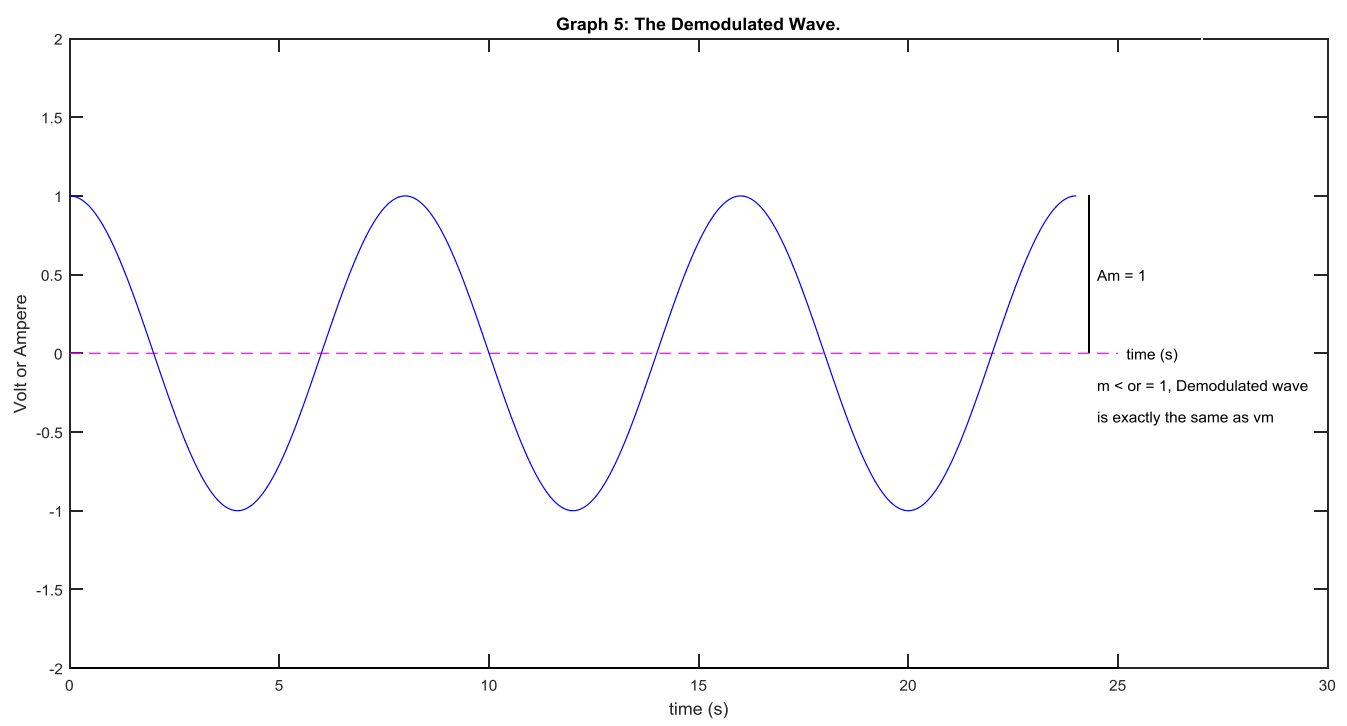

Fig 9: Graph 5 for $A_{m}=1 ; m=0.5$. 


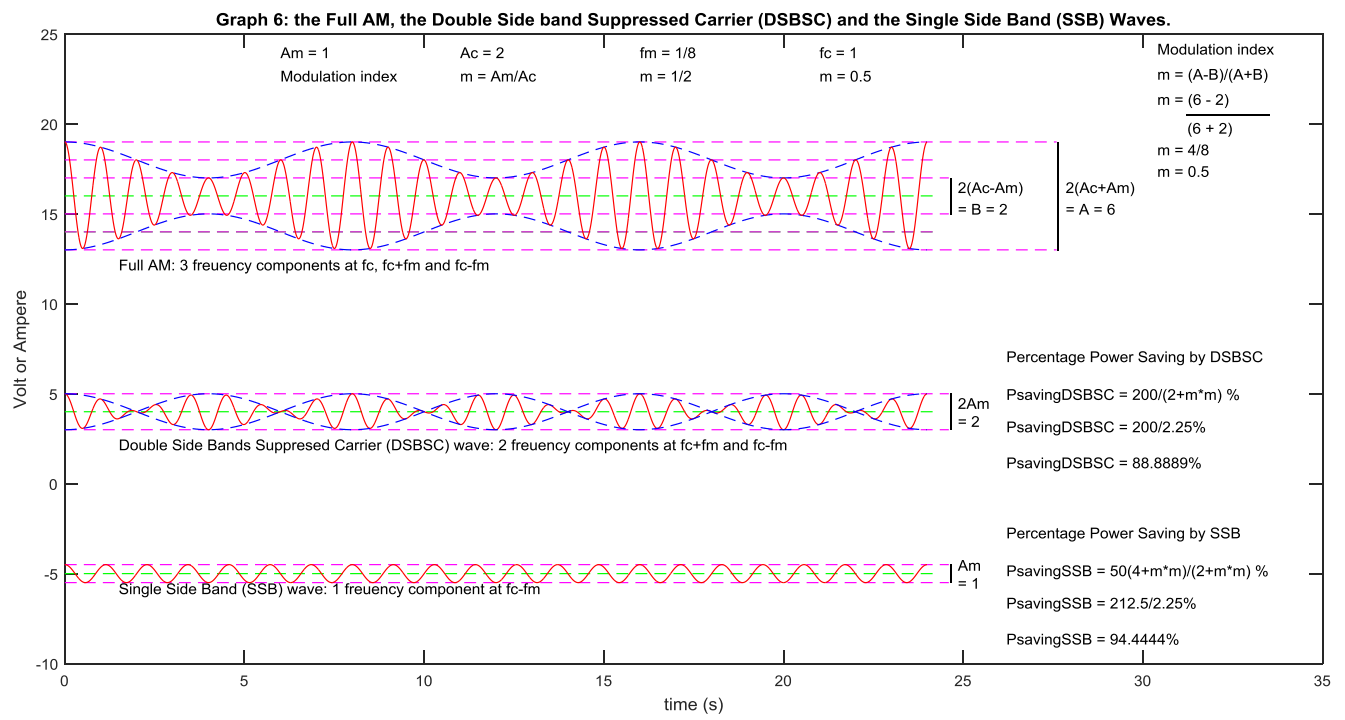

Fig 10: Graph 6 for $A_{m}=1 ; m=0.5$.

The $\mathrm{x}$-axis or the time axis or $0 \mathrm{~V} / \mathrm{A}$ line for the Modulating Signal, the Carrier Signal, the Amplitude Modulated wave, and the Demodulated wave are raised to $21 \mathrm{~V}, 14 \mathrm{~V}, 5 \mathrm{~V}$, and $6 \mathrm{~V}$, respectively so that the four can be viewed together on the same Graph 1 as one window. For clarity, the four signals are also shown individually in Graphs 2, 3, 4, and 5 (Figs. 6, 7, 8, and 9 , respectively).

Graph 6 (Fig. 10) shows the waveforms of the Full AM (Amplitude Modulated wave), Double Side Band suppressed Carrier (DSBSC) signal, and the Single Side Band (SSB) signal on the same graph sheet. The $\mathrm{x}$-axis or the time axis or 0 V/A line for the Full AM, Double Side Band suppressed Carrier (DSBSC) wave, and the Single Side Band (SSB) wave are raised to $16 \mathrm{~V}, 4 \mathrm{~V}$, and $-5 \mathrm{~V}$, respectively so that the three can be viewed together on the same Graph 6 as one window.

Graph 1 (Fig. 5) also displays the frequencies and maximum amplitudes of both the Modulating Signal and the Carrier Signal. The wide peak-to-peak A and the narrow peak-to-peak $\mathrm{B}$ of the Amplitude Modulated wave are also indicated in Graph 1 (Fig. 5). Computations of the modulation index using Eqns. (6) and (14) are shown in Graph 1 (Fig. 5). Both equations are found to give the same value of the modulation index each time the program was run.

A careful study of the Amplitude Modulated wave in Graph 1 (Fig. 5) and Graph 4 (Fig. 8) shows that an upper envelope and a lower envelope are formed by the peaks of the Amplitude Modulated wave. The upper envelope is the same as the Modulating Signal while the lower envelope is exactly the Modulating Signal inverted upside down. For m less or equal to one, the two envelopes do not overlap. More details on the Amplitude Modulated wave are also displayed in Graph 4 (Fig. 8).

After the Amplitude Modulated wave arrived at the receiver, Amplitude Demodulation takes place by simply detecting and extracting the upper envelope as the Amplitude Demodulated wave which is shown in Graph 1 (Fig. 5) and Graph 5 (Fig. 9). For $m$ less than one, the two envelopes do not overlap and the
Amplitude Demodulated wave is the same as the Modulating Signal. The narrow peak-to-peak B is the separation or gap between the upper and lower envelopes. For $m$ less than or equal to one, $\mathrm{A}_{\mathrm{c}}-\mathrm{A}_{\mathrm{m}}$ is greater than $0, \mathrm{~B}$ is also greater than 0 , the Modulating Signal is recoverable as stated in Graph 4 (Fig. 8) and Graph 5 (Fig. 9).

Graph 1 for $\mathrm{A}_{\mathrm{m}}=0.5(\mathrm{~m}=0.25), \mathrm{A}_{\mathrm{m}}=1(\mathrm{~m}=0.5), \mathrm{A}_{\mathrm{m}}=1.5$ $(\mathrm{m}=0.75), \mathrm{A}_{\mathrm{m}}=1.7(\mathrm{~m}=0.85), \mathrm{A}_{\mathrm{m}}=1.85(\mathrm{~m}=0.925)$, and $A_{m}=2(m=1)$ are presented in Figs. 11, 5, 12, 13, 14, and 15, respectively. The higher the value of $m$ the smaller the gap between the upper and lower envelopes on the Amplitude Modulated wave. At $\mathrm{m}$ equals 1 , the two envelopes touch each other as seen in Fig. 15. The upper envelope is correctly detected and extracted as the Amplitude Demodulated wave.

As $A_{m}$ increases from 0 towards $A_{c}, m$ increases from 0 towards from $1, A_{c}-A_{m}$ decreases, the gap between the envelopes (that's the narrow peak-to-peak value, B) decreases towards 0 as illustrated in Table 1. This trend can also be viewed more clearly from Graph 4 for the various values of $\mathrm{m}$; Graph 4 is not shown here to save space. When $\mathrm{m}$ is less or equal to 1 , the accurate demodulation at the receiver is guaranteed.

\subsection{Modulation index greater than 1}

Graph 1 for $\mathrm{A}_{\mathrm{m}}=2.1(\mathrm{~m}=1.05), \mathrm{A}_{\mathrm{m}}=3(\mathrm{~m}=1.5)$, and $\mathrm{A}_{\mathrm{m}}=$ $4(\mathrm{~m}=2)$ are presented in Figs. 16, 17, and 18, respectively. For $\mathrm{m}$ greater than one, $\mathrm{A}_{\mathrm{c}}-\mathrm{A}_{\mathrm{m}}$ is negative and $\mathrm{B}$ is also negative as shown in Table 2. The upper and the lower envelopes overlap. Part of the lower envelope which is above the time axis is erroneously extracted with the upper envelope as the Amplitude Demodulated wave. The Demodulated wave is, therefore, inaccurate and distorted as shown in Figs. 16, 17, and 18 . This trend can be viewed more clearly from Graph 4 and Graph 5 for the various values of m; Graph 4 and Graph 5 are not shown here to save space. Therefore, for accurate and distortion-less demodulation at the receiver, m must not be greater than 1 . 


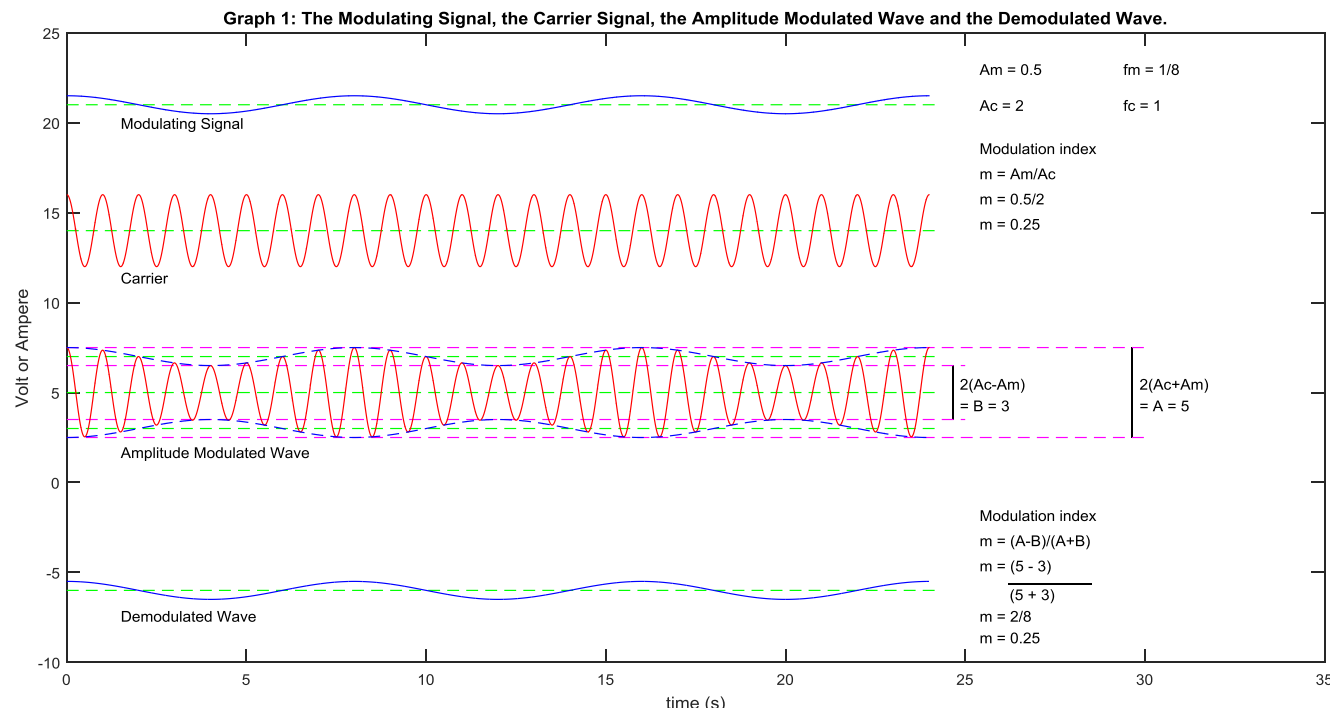

Fig 11: Graph 1 for $A_{m}=0.5 ; m=0.25$.

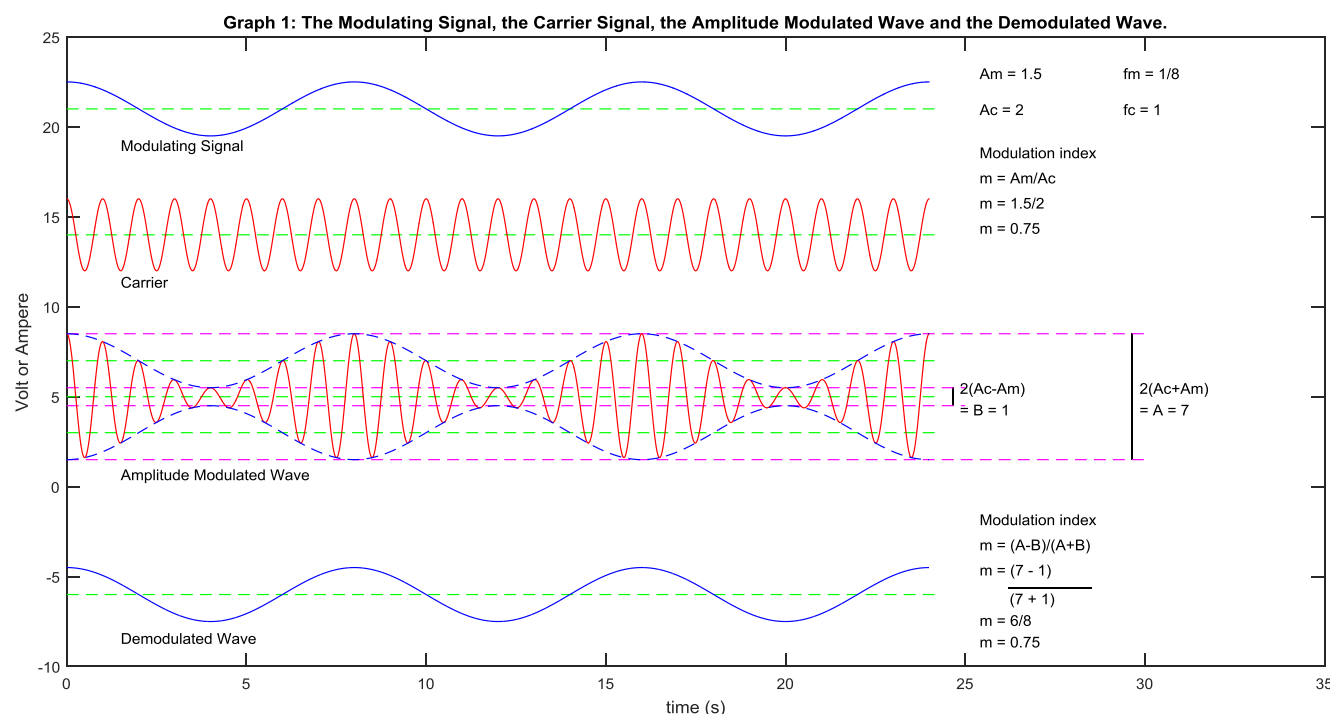

Fig 12: Graph 1 for $A_{m}=1.5 ; m=0.75$.

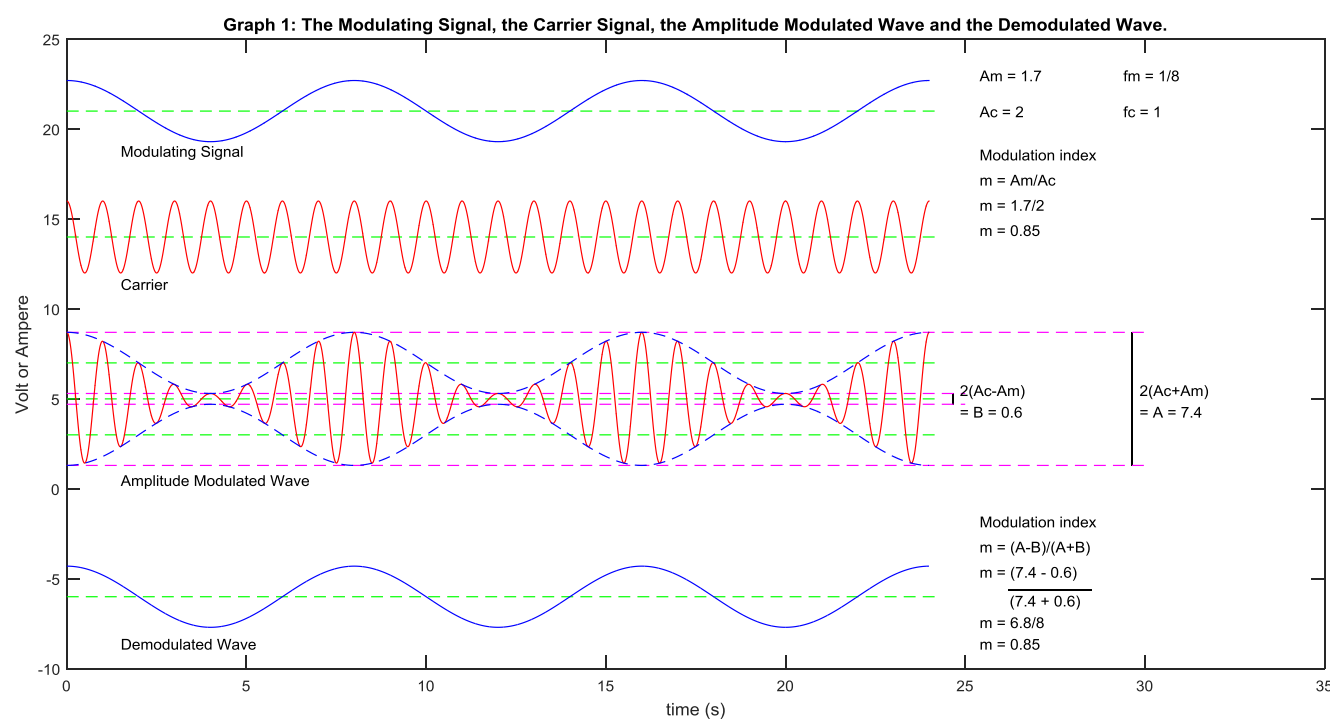

Fig. 13 Graph 1 for $A_{m}=1.7 ; m=0.85$. 


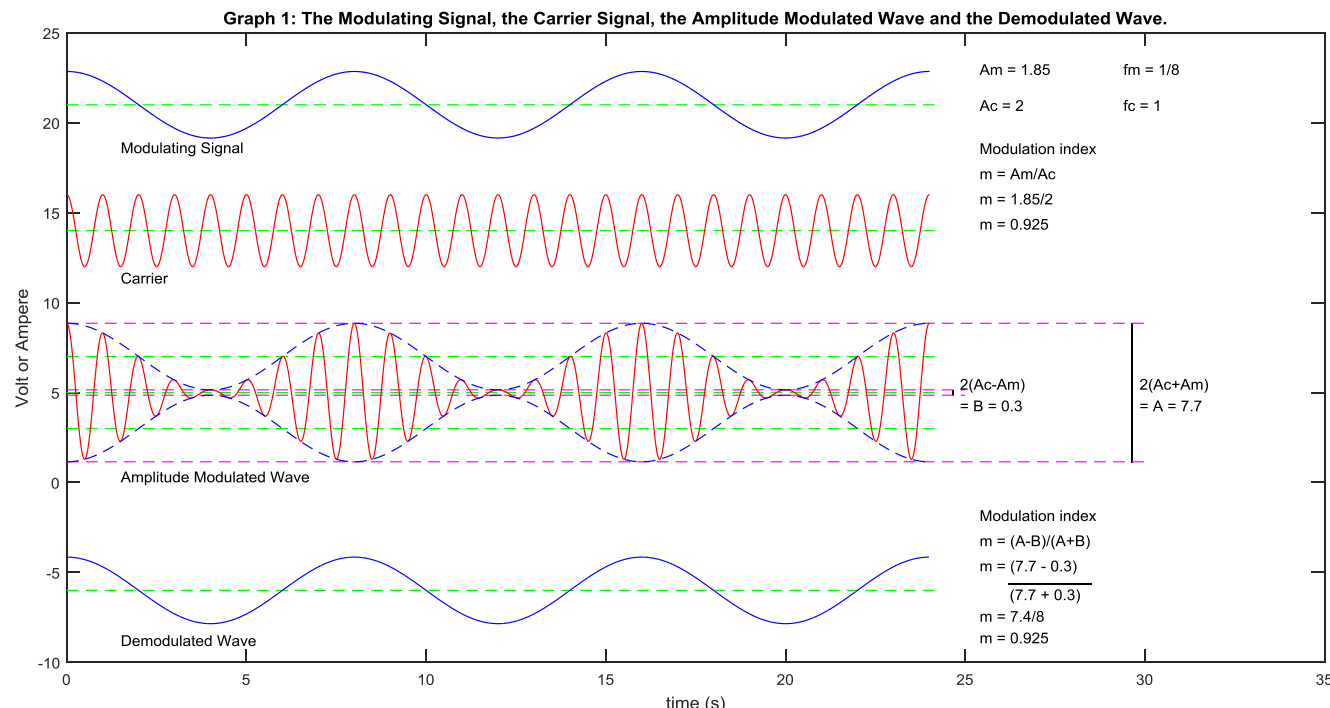

Fig 14: Graph 6 for $A_{m}=1.85 ; m=0.925$.

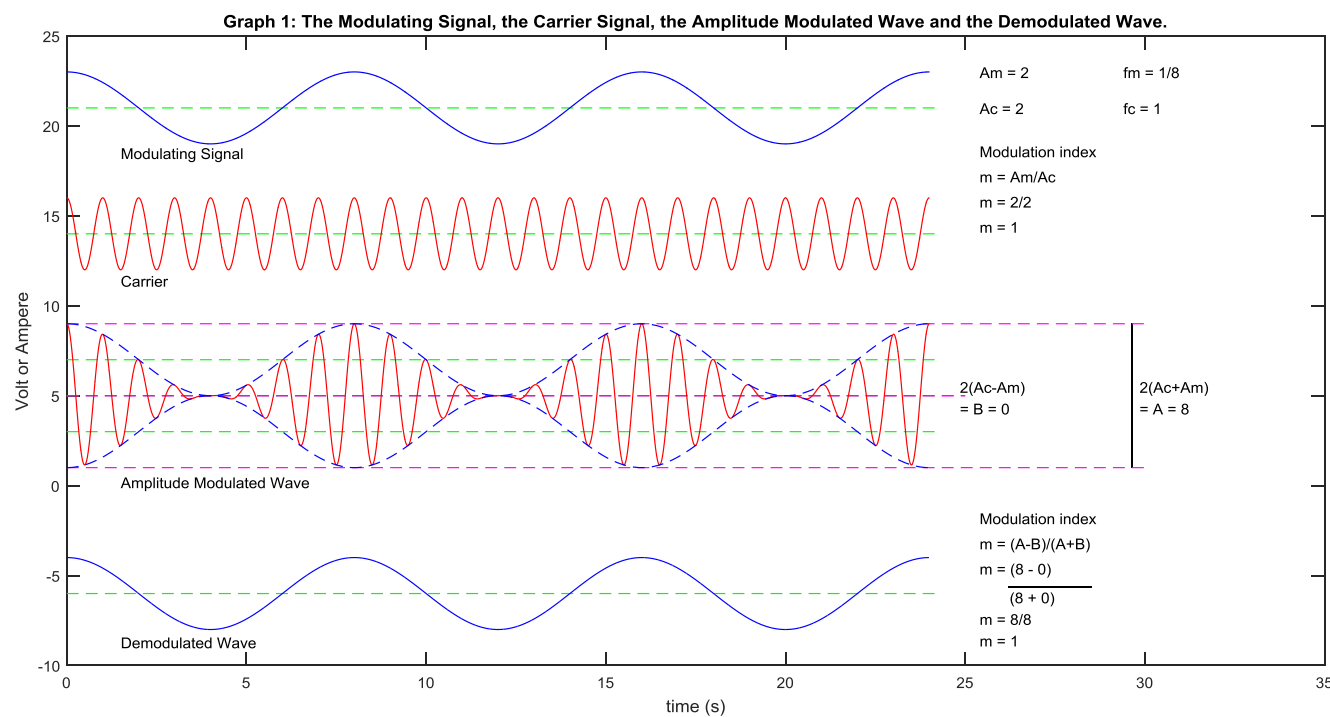

Fig 15: Graph 1 for $A_{m}=2 ; m=1$.

Table 1. Amplitude Modulation Results with $\mathbf{m} \leq 1$

\begin{tabular}{|c|c|c|c|c|c|c|}
\hline $\mathrm{S} / \mathrm{N}$ & $\mathrm{A}_{\mathrm{m}}$ & $\mathrm{m}$ & $\mathrm{A}_{\mathrm{c}}-\mathrm{A}_{\mathrm{m}}$ & $\mathrm{B}$ & $\begin{array}{c}\text { Overlapping of Upper } \\
\text { and Lower Envelopes }\end{array}$ & $\begin{array}{c}\text { Accurate and } \\
\text { Distortion-less } \\
\text { Demodulation }\end{array}$ \\
\hline 1 & 0.50 & 0.250 & 1.50 & 3.0 & No & Yes \\
\hline 2 & 1.00 & 0.500 & 1.00 & 2.0 & No & Yes \\
\hline 3 & 1.50 & 0.750 & 0.50 & 1.0 & No & Yes \\
\hline 4 & 1.70 & 0.850 & 0.30 & 0.6 & No & Yes \\
\hline 5 & 1.85 & 0.925 & 0.15 & 0.3 & No & Yes \\
\hline 6 & 2.00 & 1.000 & 0.00 & 0.0 & No & \\
\hline
\end{tabular}




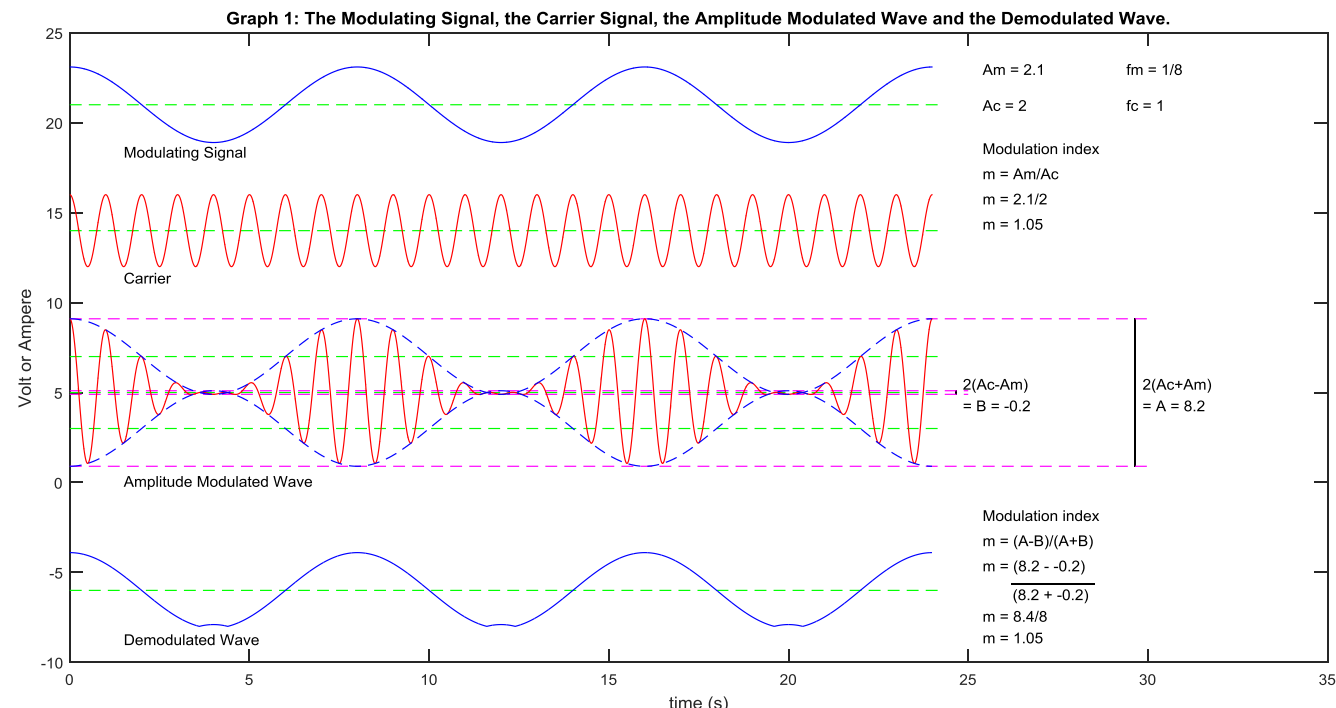

Fig 16: Graph 1 for $A_{m}=2.1 ; m=1.05$.

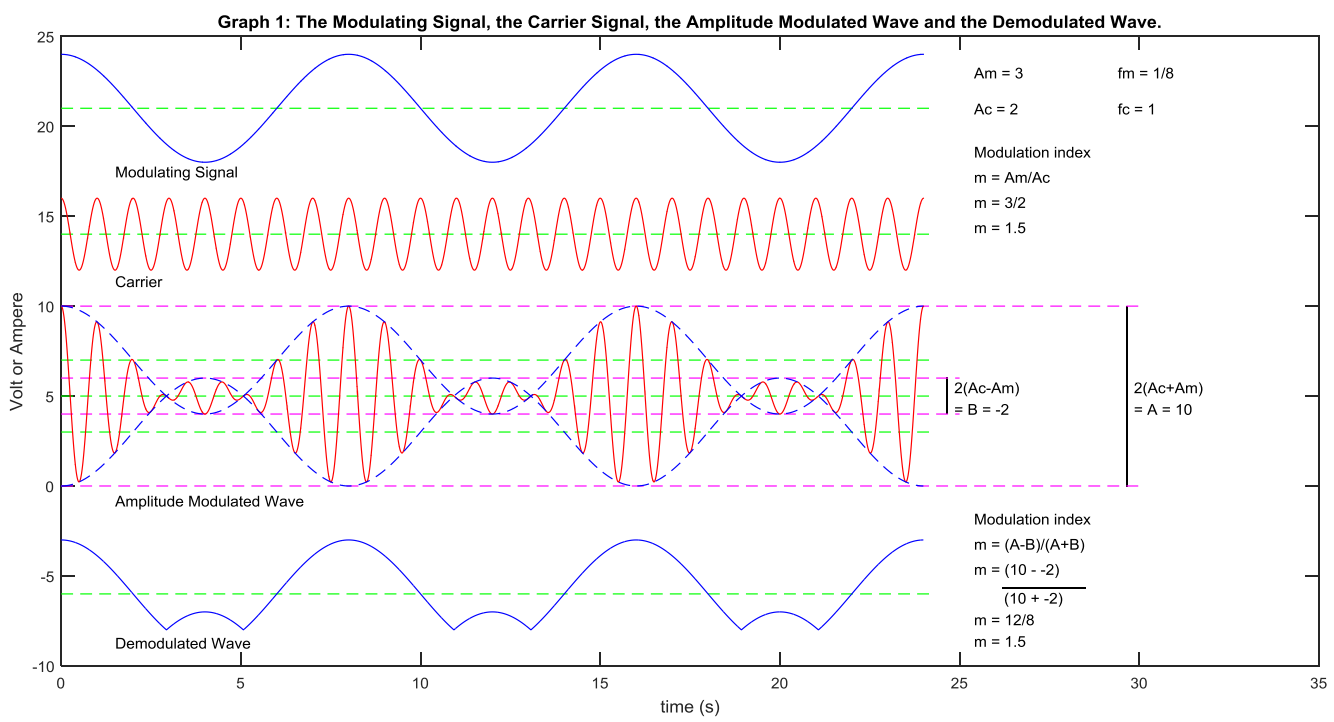

Fig 17: Graph 1 for $A_{m}=3 ; m=1.5$.

Table 2. Amplitude Modulation Results with $\mathbf{m}>1$

\begin{tabular}{|c|c|c|c|c|c|c|}
\hline $\mathrm{S} / \mathrm{N}$ & $\mathrm{A}_{\mathrm{m}}$ & $\mathrm{m}$ & $\mathrm{A}_{\mathrm{c}}-\mathrm{A}_{\mathrm{m}}$ & $\mathrm{B}$ & $\begin{array}{c}\text { Overlapping of Upper } \\
\text { and Lower Envelopes }\end{array}$ & $\begin{array}{c}\text { Accurate and } \\
\text { Distortion-less } \\
\text { Demodulation }\end{array}$ \\
\hline 1 & 2.10 & 1.05 & -0.10 & -0.20 & Yes & No \\
\hline 2 & 3.00 & 1.50 & -1.00 & -2.00 & Yes & No \\
\hline 3 & 4.00 & 2.00 & -2.00 & -4.00 & Yes & No \\
\hline
\end{tabular}

\subsection{Full AM, DSBSC and SSB}

Graph 6 for $A_{m}=0.5(m=0.25), A_{m}=1(m=0.5), A_{m}=1.5$ $(\mathrm{m}=0.75), \mathrm{A}_{\mathrm{m}}=1.7(\mathrm{~m}=0.85), \mathrm{A}_{\mathrm{m}}=1.85(\mathrm{~m}=0.925)$, and $A_{m}=2(m=1)$ are presented in Figs. 19, 10, 20, 21, 22, and 23 , respectively. The modulation index and percentage power- saving by DSBSC and SSB were computed and indicated in Graph 6. The peak-to-peak values of the three signals are also indicated on Graph 6. The results are summarized in Table 3. Percentage power-saving by SSB is greater than the percentage power-saving by DSBSC. The smaller the modulation index, the greater the percentage power-saving. 


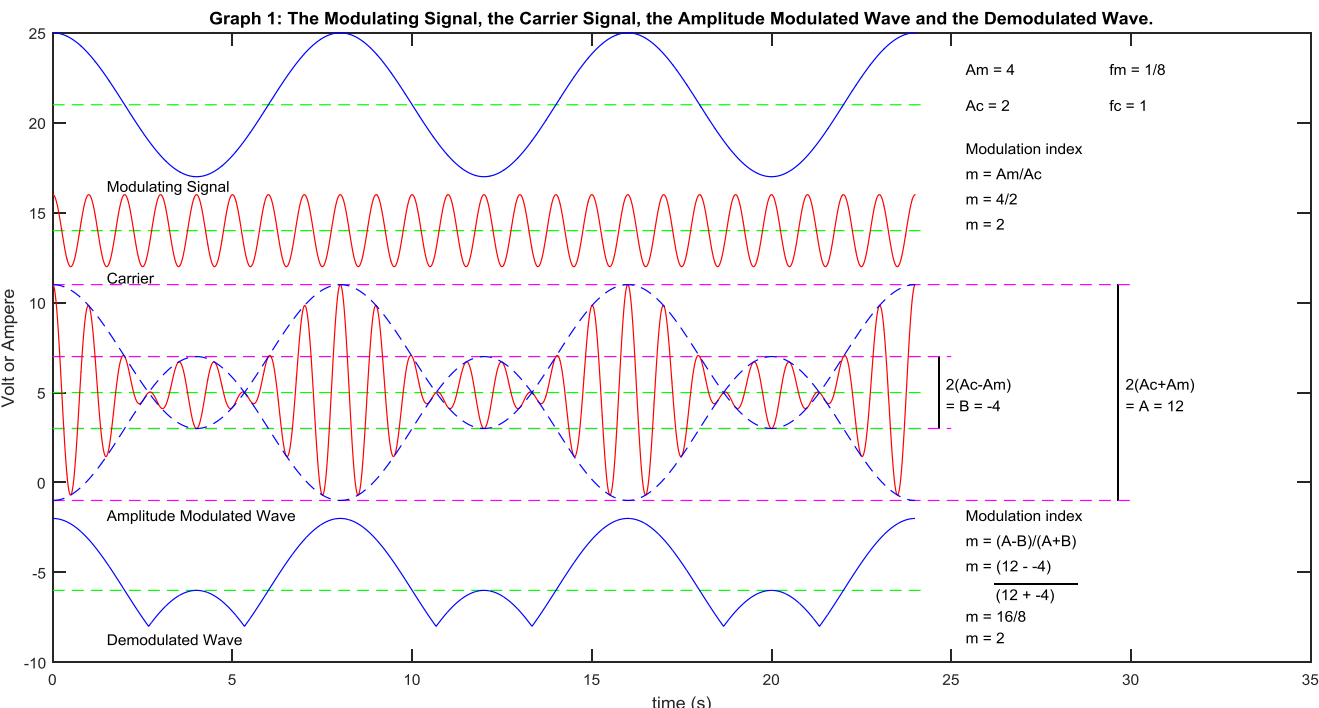

Fig.18: Graph 1 for $A_{m}=4 ; m=2$.

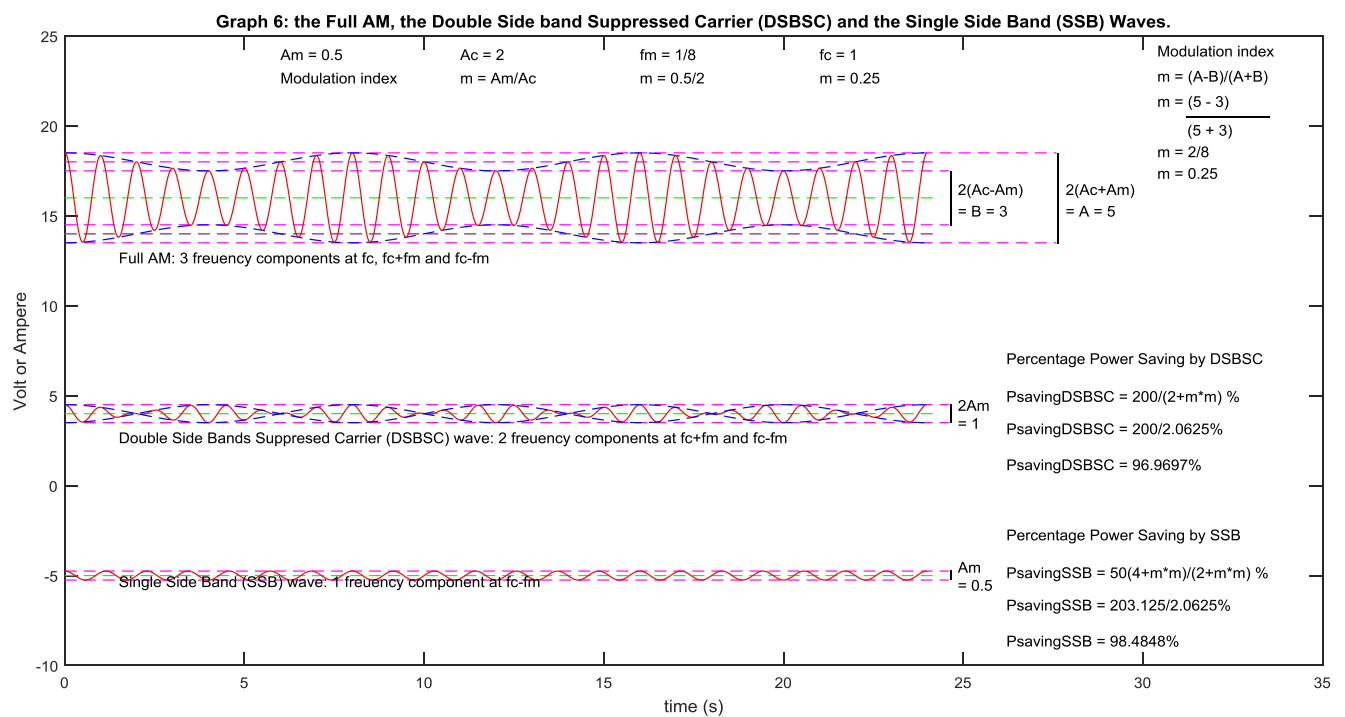

Fig 19: Graph 6 for $A_{m}=0.5 ; m=0.25$.

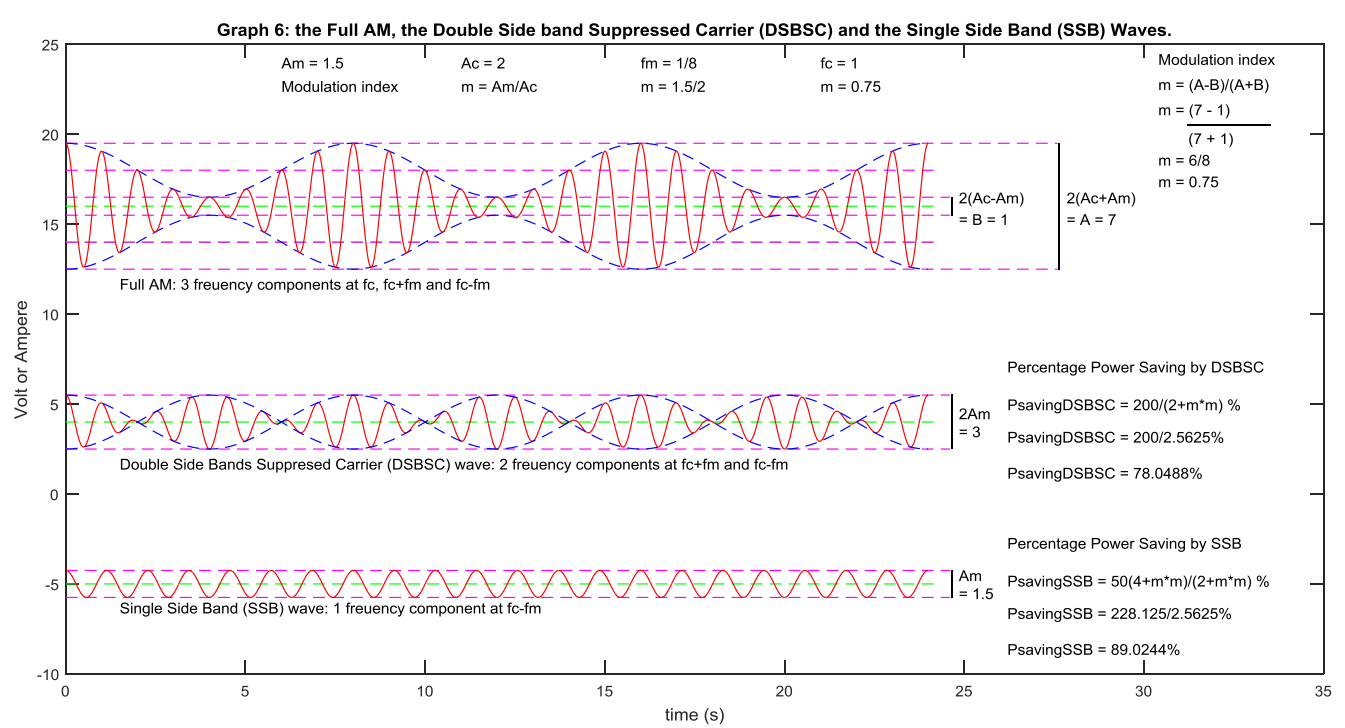

Fig 20: Graph 6 for $A_{m}=1.5 ; m=0.75$. 


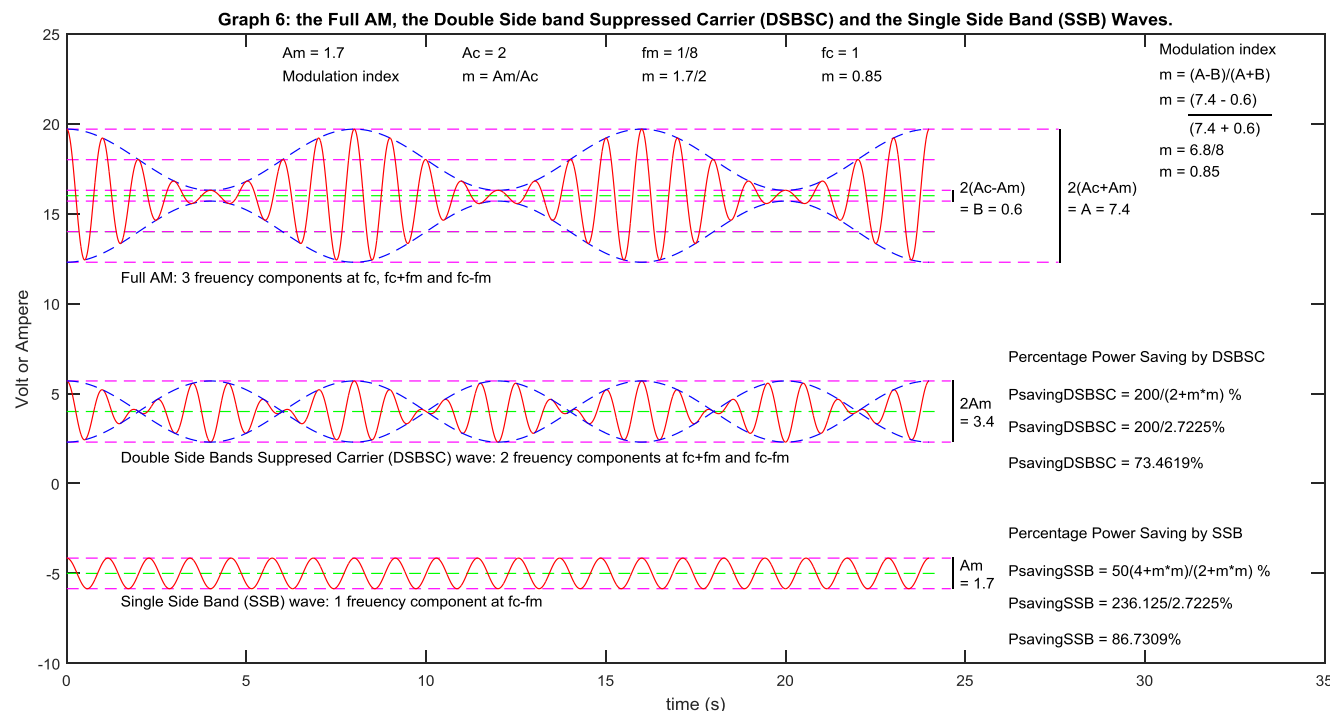

Fig 21: Graph 6 for $A_{m}=1.7 ; m=0.85$.

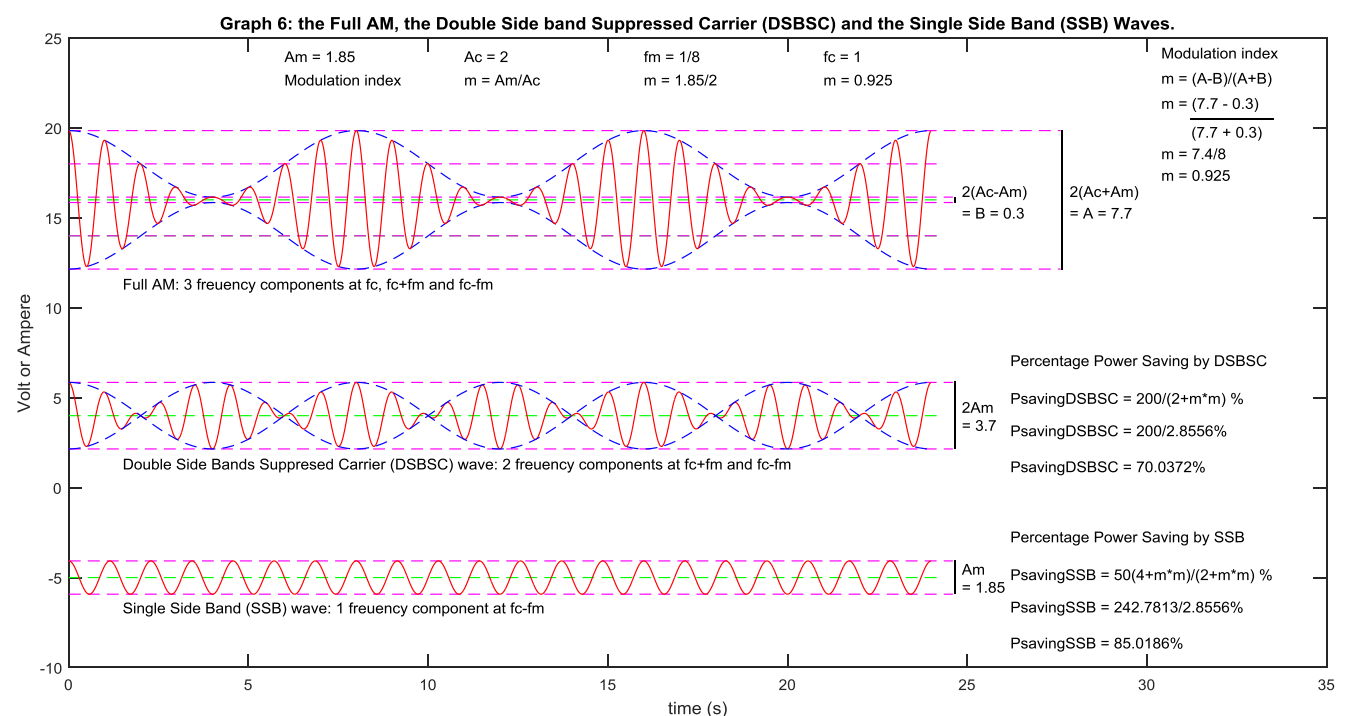

Fig 22: Graph 6 for $A_{m}=1.85 ; m=0.925$.

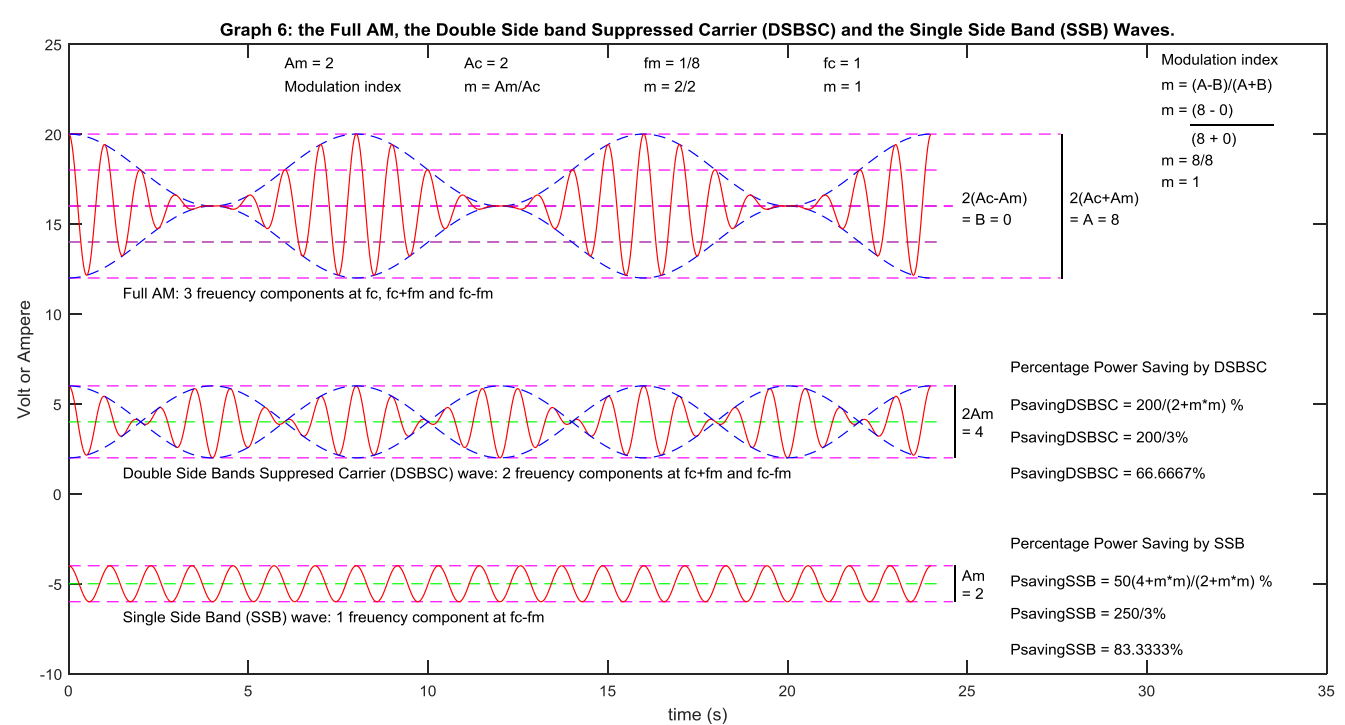

Fig 23. Graph 6 for $A_{m}=2 ; m=1$. 
Table 3. Full AM, DSBSC and SSB Results with $\mathrm{m} \leq 1$

\begin{tabular}{|c|c|c|c|c|c|c|c|}
\hline \multirow[t]{2}{*}{$\mathrm{S} / \mathrm{N}$} & \multirow[t]{2}{*}{$\mathrm{A}_{\mathrm{m}}$} & \multirow[t]{2}{*}{$\mathrm{m}$} & \multirow{2}{*}{$\begin{array}{c}\text { Full AM } \\
\text { peak-to-peak } \\
A=2 A_{c}+2 A_{m}\end{array}$} & \multicolumn{2}{|c|}{ DSBSC } & \multicolumn{2}{|c|}{ SSB } \\
\hline & & & & $\begin{array}{c}\text { peak-to-peak } \\
=2 \mathrm{~A}_{\mathrm{m}}\end{array}$ & $\begin{array}{c}\% \text { Power- } \\
\text { saving }\end{array}$ & $\begin{array}{c}\text { peak-to-peak } \\
\quad=A_{m}\end{array}$ & $\begin{array}{c}\% \text { Power- } \\
\text { saving }\end{array}$ \\
\hline 1 & 0.50 & 0.250 & 5.0 & 1.0 & 96.97 & 0.50 & 98.48 \\
\hline 2 & 1.00 & 0.500 & 6.0 & 2.0 & 88.89 & 1.00 & 94.44 \\
\hline 3 & 1.50 & 0.750 & 7.0 & 3.0 & 78.05 & 1.50 & 89.02 \\
\hline 4 & 1.70 & 0.850 & 7.4 & 3.4 & 73.46 & 1.70 & 86.73 \\
\hline 5 & 1.85 & 0.925 & 7.7 & 3.7 & 70.04 & 1.85 & 85.02 \\
\hline 6 & 2.00 & 1.000 & 8.0 & 4.0 & 66.67 & 2.00 & 83.33 \\
\hline
\end{tabular}

\section{CONCLUSIONS}

A computer program has been developed as a teaching aid for Amplitude Modulation Theory. Transfer of teaching from physical classes to virtual classes to prevent the spread of COVID-19 has been enhanced with a user-friendly Programmable Teaching Aid. Students can generate illustrative Graphs on their own at their safe locations. These graphs illustrate the basic concepts of the Amplitude Modulation theory. By simply changing the maximum amplitude of the Modulating Signal, the students can study or perform experiments remotely and individually on the effect of change of modulation index on the amplitude modulation process and the possibility or otherwise of the accurate recovery of the Modulating Signal at the receiver. Computations of the modulation index, peak-to-peak value, and power-saving are demonstrated. This teaching aid has the potential of stimulating the interest of students on the subject. Furthermore, it enables students' participation in the virtual classroom as it provides some "do it yourself" tasks. Development of similar Programmable Teaching Aids is recommended for other science and engineering topics to make teaching at a distance and learning at a distance effective. This will reduce the adverse effect of COVID-19 lockdown and social distancing on education.

\section{REFERENCES}

[1] Tesini, L. B. 2020. Coronavirus and acute respiratory syndromes (COVID-19, MERS, and SARS); MSD Manual, Professional Edition available: www.msdmanuals.com/professional/infectiousdiseases/respiratory-viruses/coronaviruses-and-acuterespiratory-syndrome-covid-19-mers-and-sars

[2] Sahu, P. K. 2020. "Closure of Universities Due to Coronavirus Disease 2019 (COVID-19): Impact on Education and Mental Health of Students and Academic Staff', Cureus 12(4), 1-6.

[3] Guo, Y., Cao, Q., Zhong-Si Hong, Z., Tan, Y., Chen, S., Jin, H., Tan, K., Wang, D., and Yan, Y. 2019. "The origin, transmission and clinical therapies on coronavirus disease 2019 (COVID-19) outbreak - an update on the status", Military Medical Research 7(11), $1-10$.

[4] Ohia, C., Bakarey, A. S., and Ahmad, T. 2020.
"COVID-19 and Nigeria: putting the realities in context International Journal of Infectious Diseases", 95, 279281.

[5] Kushwaha, S. 2020. "A Research on Coronal Virus Disease 2019 (COVID-19)", International Research Journal of Engineering and Technology (IRJET), 55785586.

[6] Singh, M. 2020. "COVID -19 (by SARS-CoV-2) an Endemic to Pandemic: A Review", International Journal of Scientific \& Engineering Research, 11(7), 267278.

[7] Lone, S. A. and Ahmad, A. 2020. "COVID-19 pandemic - an African perspective", Emerging Microbes \& Infections, 9(1), 13001308.

[8] Anjorin, A. A. 2020. "The coronavirus disease 2019 (COVID-19) pandemic: A review and an update on cases in Africa", Asian Pacific Journal of Tropical Medicine, 13(5), 199-203.

[9] Bedford, J., Enria, D., Giesecke, J., Heymann, D. L., Ihekweazu, C., Kobinger, G., Lane, H. C., Memish, Z., Oh, M., Sall, A. A., Schuchat, A., Ungchusak, K., and Wieler, L. H. 2020. "COVID-19: towards controlling of a pandemic”, Lancet, 395(10229), 1015-1018.

[10] Agusi, E. R., Ijoma, S. I., Nnochin, C. S., Njoku-Achu, N. O., Nwosuh, C. I., and Meseko, C. A. "The COVID19 pandemic and social distancing in Nigeria: ignorance or defiance", Pan Africa Medical Journal, 35(2):52, 1-3.

[11] Anyanwu, M .U., Festus, I. J., Nwobi, O. C., Jaja, C. I. and Oguttu, J. W. 2020. A Perspective on Nigeria's Preparedness, Response and Challenges to Mitigating the Spread of COVID-19, Challenges, 11(22):1-15.

[12] Stephen, O. and Omonyemen, O. 2020. "COVID-19 pandemic outbreak and government policy on educational infrastructure in Nigeria", The International Journal of Indian Psychology, 8(2), 1010-1022.

[13] Hussain, T. A. 2020. "Education and COVID-19 in Nigeria: Tackling the Digital Divide", available: https://worldliteracyfoundation.org/education-andcovid-19-in-nigeria/ 
[14] Burgess, S. and Sievertsen, H. H. 2020. "Schools, skills, and learning: The impact of COVID-19 on education", available: https://voxeu.org/article/impact-covid-19education

[15] Ravi, R. C. 2020. "Lockdown of colleges and universities due to COVID-19: Any impact on the educational system in India?", Journal of Education and Health Promotion, 9(1), 209-211.

[16] IESALC-UNESCO. 2020. "COVID-19 and higher education: Today and tomorrow Impact analysis, policy responses and recommendations", 1-46, available: http://www.iesalc.unesco.org/en/wpcontent/uploads/2020/04/COVID-19-EN-090420-2.pdf

[17] Mustafa, N. 2020. "Impact of The 2019-20 Coronavirus Pandemic on Education", International Journal of Health Preference Research, 5(20):31-44.

[18] Gewin, V. 2020. "Five tips for moving teaching online as COVID-19 takes hold", Nature, 580, 295-296.

[19] Rao, P. and A. Modi, A. 2020. "Movement from Classroom to Webroom. An Analysis of Students' ELearning Readiness and Initiatives Taken to Prepare the Learners for the Migration", International Journal of Scientific \& Engineering Research, 11(7), 1060-1063.

[20] Lim, M. 2020. "Educating despite the COVID-19 outbreak: lessons from Singapore", available: https://www.timeshighereducation.com/blog/educatingdespite-covid-19-outbreak-lessons-singapore

[21] Timmis, S., Broadfoot, P., Sutherland, R. and Oldfield, A. 2016. "Rethinking assessment in a digital age: opportunities, challenges and risks", Br Educ Res J., 42:454-476.

[22] Mwenisongole, C. L., Mulengeki, F. M., and Mkuchu, S. V. 2020. "Teachers and students strategies to enhance teaching and learning through Information Communication Technology at Technical Vocational Education Training in Tanzania", International Journal of Scientific \& Engineering Research, 11(7), 13901410 .

[23] Kumar, S. 2017. "Teaching materials and teaching aids - 1 (teaching material)", ePGPathshala. 12.2016.

[24] Sivakumar, R. 2014. "Impact of Low Cost Teaching Aids in Teaching Science", Innovative Thoughts International Research Journal, 2(3), 31-36.

[25] Wellspring. 2020. "Teaching Aids Key to Quality Education", available: https://thewellspringfoundation.org/stories/teachingaids-key-to-quality-education/

[26] Zubair, A.R. and Ahmed Y.K. 2019. "Engineering Education: Computer-Aided Engineering with MATLAB; Discrete Wavelet Transform as a Case Study", International Journal of Computer Applications, 182(46), 6-17.
[27] Chiovoloni, M. 2004. "The interactive power of local and traditional communication systems", Ilea Magazine, 1-4.

[28] Cachon, J. 2015. "Ancient Indigenous Communication: An Exploratory Multidisciplinary Model”, International Journal of Diverse Identities, 15(2), 1-33.

[29] Dima, I. C., Teodorescu, M., and Gîfu, D. 2014. "New communication approaches vs. traditional communication", International Letters of Social and Humanistic Sciences, 20(2014), 46-55.

[30] Ògúndèjí, P. A. 1997. "The Communicative and Semiotic Contexts of àrokò among the Yoruba SymbolCommunication Systems", African Languages and Cultures, 10(2), 145-156.

[31] Umesh Sinha, U. 1988. Principles of communication. Satya Prakashan: New Delhi.

[32] Kenney, G. and Davis, B. 1992. Electronic Communication Systems. Macmillan/McGraw-Hill.

[33] Chaparro, L. F. and Akan, A. 2019. "Continuous-Time Systems", chapter 2 in book: Signals and Systems Using MATLAB (Third edition), 115-165.

[34] Frenzel L. E. 2018. "Radio/Wireless: The Invisible Cables of Modern Electronics", chapter 7 in book: Electronics Explained: Fundamentals for Engineers, Technicians, and Makers, 159-194.

[35] Faruque, S. 2017. Radio Frequency Modulation Made Easy. Springer Nature, Switzerland.

[36] Zubair A. R. 2009. "Numerical Integration Based Analysis of Pulse Width Modulated Voltage Source Inverter", In A. Gyasi-Agyei and T. Ogunfunmi (Eds.). Adaptive Science and Technology: Proceedings of the 2nd IEEE International Conference on Adaptive Science and Technology (ICAST). 14-16 December, 2009. Accra, 301-307. Available at https://ieeexplore.ieee.org/document/5409707.

[37] MathWorks (Matlab). 2018. "Documentation for MathWorks products" Available: https://ch.mathworks.com/help/index.html.

[38] Zubair A. R. and Olatunbosun A. 2014. "Computer Aided Root-Locus Numerical Technique", Nigerian Journal of Technology, 33(1), 1-13.

[39] Hahn B. and Valentine D. T. 2007. Essential MATLAB for Engineers and Scientists. Burlington: Elsevier.

[40] Zubair A. R. and Olatunbosun A. 2014. "Arithmetic and Logical Models of Transmission Line Stranded Conductors for Voltage and Voltage-Drop Analysis", International Journal of Innovation and Scientific Research, 8(2), 200-209. 


\section{APPENDIX}

\section{ProgT-Aid_AM}

\% Dr. A. R. Zubair; ar.zubair@ui.edu.ng;

ar.zubair@yahoo.co.uk;

$\%$ Teaching Aid for Amplitude Modulation Theory

$\%$ under Electronic Communication aspect of

$\%$ Electrical and Electronic Engineering

$\%$ Name of program: ProgT-Aid_AM

$\%$ Dear Students, please keep staying safe against COVID-19 pandemic.

$\%$ Study at your save location.

$\% 6$ Graphs will be produced by this program as outputs.

$\%$ Maximize the graphs for better viewing.

$\%$ Set the value of the maximum amplitude Am of the

Modulating signal.

$\%$ Choose any value between 0 to 4 . Replace the value next line.

$\mathrm{Am}=1$

$\%$ change $A m=1$; above to $A m=x$; where $\mathrm{x}$ is between 0 and

$\%$ Re-save the program and run the program.

$\%$ The maximum amplitude Ac of the Carrier signal is fixed at 2 . Do not change it.

$\mathrm{Ac}=2$;

$\%$ the Carrier frequency is fixed at $1 \mathrm{~Hz}$ while the Modulating signal frequency is fixed at $1 / 8 \mathrm{~Hz}$.

$\%$ The Carrier frequency is 8 times the Modulating signal frequency. Do not change them.

$\mathrm{fm}=1 / 8 ; \mathrm{fc}=1$;

$\%$ Note: these values are chosen for the convenience of this teaching aid.

$\%$ In practice, Communication Engineers can choose values appropriate for

$\%$ the system

$\%$ Students do not need to read beyond this line. Do not change anything in

$\%$ the program except changing $A m=1$; to $A m=x$; where $\mathrm{x}$ is between 0 and 4 .

$\%$ Modulating signal waveform

for $\mathrm{k}=1: 3000$

$\mathrm{t}(\mathrm{k})=(\mathrm{k}-1) * 8 / 1000$;

$\mathrm{vm}(\mathrm{k})=21+\mathrm{Am} * \cos (2 * \mathrm{pi} * \mathrm{fm} * \mathrm{t}(\mathrm{k}))$;

end

$\mathrm{vm} 1=\mathrm{vm}-21$

$\mathrm{dd}=\left[\begin{array}{ll}0 & 24.2\end{array}\right] ;$ ee $=\left[\begin{array}{ll}21 & 21\end{array}\right]$;

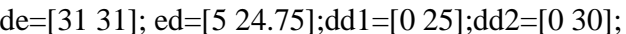

$\mathrm{ae}=[24.6524 .65] ; \mathrm{ea}=[5+\mathrm{Ac}-\mathrm{Am}$ 5-Ac+Am];

ae $1=[29.6529 .65] ;$ ea $1=[5+A c+A m$ 5-Ac-Am $]$;

$\%$ Carrier signal waveform

for $\mathrm{k}=1: 3000$

$\mathrm{vc}(\mathrm{k})=14+\mathrm{Ac} * \cos (2 * \mathrm{pi} * \mathrm{fc} * \mathrm{t}(\mathrm{k}))$;

end

$\mathrm{vc} 1=\mathrm{vc}-14$

$\%$ Amplitude Modulated wave

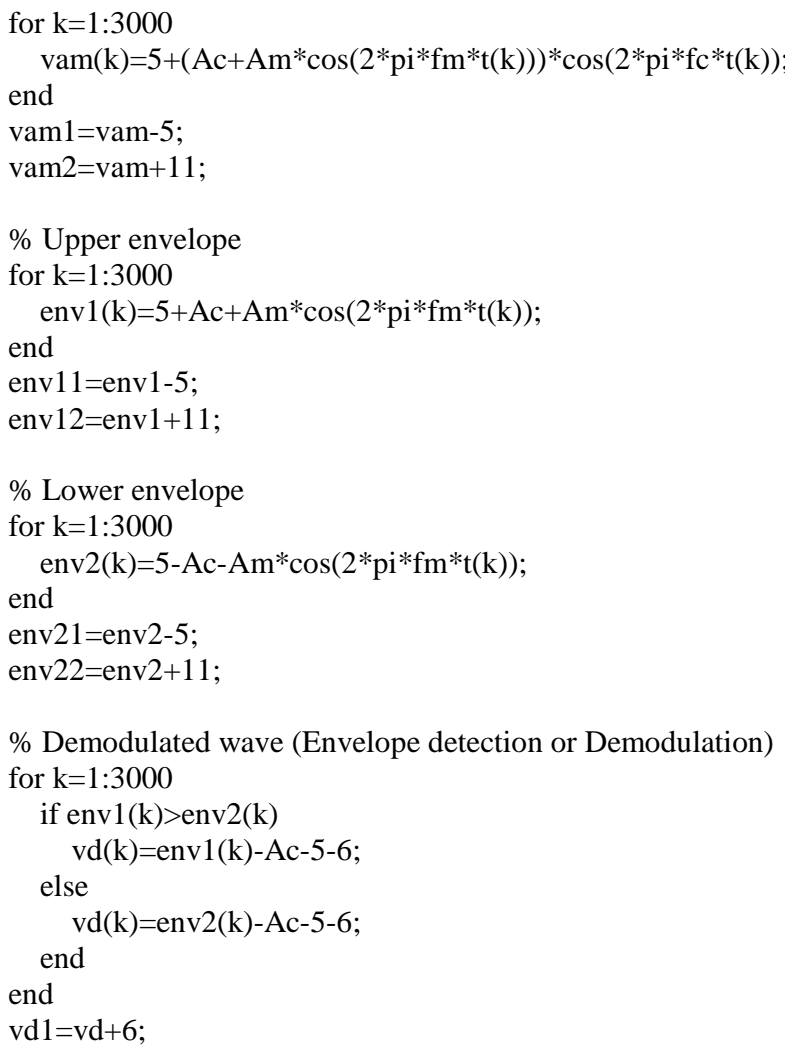

$\%$ Plot the modulating signal, the carrier signal, the amplitude modulated

$\%$ wave and the demodulated wave on the same graph. Graph

ee1 $=\left[\begin{array}{ll}14 & 14\end{array}\right]$

ee2 $=[55]$;

ee $3=[5+\mathrm{Ac} 5+\mathrm{Ac}]$

ee $4=[5+\mathrm{Ac}+\mathrm{Am} 5+\mathrm{Ac}+\mathrm{Am}]$

ee $5=[5+$ Ac-Am $5+$ Ac-Am $]$

ee $6=[5-A c 5-A c]$;

ee $7=[5-A c+A m 5-A c+A m]$

ee8 $=[5-\mathrm{Ac}-\mathrm{Am}$ 5-Ac-Am];

ee $9=[-6-6]$;

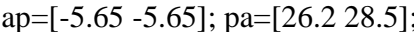

plot (dd,ee,'g--')

hold

plot (ae,ea,'k-')

plot (ae1,ea1,'k-')

plot (de,ed,'w--')

plot (dd,ee 1,'g--')

plot (dd,ee2,'g--')

plot (dd,ee3,'g--')

plot (dd2,ee4,'m--')

plot (dd1,ee5,'m--')

plot (dd,ee6,'g--')

plot (dd1,ee7,'m--')

plot (dd2,ee8,'m--')

plot (dd,ee9,'g--')

plot (pa,ap,'k-')

$\operatorname{plot}\left(\mathrm{t}, \mathrm{vm}, \mathrm{b}^{-}\right)$

$\operatorname{plot}\left(\mathrm{t}, \mathrm{vc}, \mathrm{rr}^{-}\right)$

plot(t,vam,'r-')

plot(t,env1,'b--')

plot(t,env2,'b--') 
$\operatorname{plot}(\mathrm{t}, \mathrm{vd}, \mathrm{b}-\mathrm{-})$

\% Add text, labels and titles to Graph 1

title('Graph 1: The Modulating Signal, the Carrier Signal, the Amplitude Modulated Wave and the Demodulated Wave.') xlabel('time (s)')

ylabel('Volt or Ampere')

text(1.5,17+3.5-Am,'Modulating Signal')

text $\left(1.5,11.4\right.$, 'Carrier'$\left.^{\prime}\right)$

$\operatorname{text}\left(24.85,5.5,2(\mathrm{Ac}-\mathrm{Am})^{\prime}\right)$

$\mathrm{B}=2 *(\mathrm{Ac}-\mathrm{Am})$;

$\operatorname{strg} 1=['=\mathrm{B}=$ ',num2str(B)];

$\operatorname{text}(24.85,4.3, \operatorname{strg} 1)$

$\operatorname{text}\left(29.85,5.5,2(\mathrm{Ac}+\mathrm{Am})^{\prime}\right)$

$\mathrm{A}=2 *(\mathrm{Ac}+\mathrm{Am})$

$\operatorname{strg} 2=['=\mathrm{A}=$ ',num2str(A)];

text $(29.85,4.3, \operatorname{strg} 2)$

$\mathrm{m}=\mathrm{Am} / \mathrm{Ac}$

text(1.5,-1.3+3.5-Am,'Amplitude Modulated Wave')

if $\mathrm{Am}<1.905$

text(1.5,-8.7+1.8-Am,'Demodulated Wave')

else

text(1.5,-8.7,'Demodulated Wave')

end

strg3=['m = ',num2str(Am),'/',num2str(Ac)];

text(25.4,18.6,'Modulation index')

$\operatorname{text}\left(25.4,17.2, \mathrm{\prime m}=\mathrm{Am} / \mathrm{Ac}^{\prime}\right)$

$\operatorname{text}(25.4,15.8, \operatorname{strg} 3)$

strg4=['m = ',num2str(Am/Ac) $]$;

text $(25.4,14.4, \operatorname{strg} 4)$

strg5=['m = (',num2str(A),' - ',num2str(B),')'];

strg6=[' (',num2str(A), + ',num2str(B),')'];

text(25.4,-1.8,'Modulation index')

$\operatorname{text}\left(25.4,-3.2, ' \mathrm{~m}=(\mathrm{A}-\mathrm{B}) /(\mathrm{A}+\mathrm{B})^{\prime}\right)$

$\operatorname{text}(25.4,-4.6, \operatorname{strg} 5)$

text $(25.4,-6.2, \operatorname{strg} 6)$

$\operatorname{strg} 7=[$ 'm = ',num2str(A-B),'/',num2str(A+B)];

text $(25.4,-7.4, \operatorname{strg} 7)$

strg8 $=[$ 'm = ',num2str $((\mathrm{A}-\mathrm{B}) /(\mathrm{A}+\mathrm{B}))]$;

text $(25.4,-8.6, \operatorname{strg} 8)$

$\operatorname{strg} 9=[$ 'Am = ',num2str(Am)];

text $(25.4,23, \operatorname{strg} 9)$

$\operatorname{strg} 10=[$ 'Ac = ',num $2 \operatorname{str}(\mathrm{Ac})]$;

text $(25.4,21, \operatorname{strg} 10)$

$\operatorname{text}\left(29.4,23,{ }^{\prime} \mathrm{fm}=1 / 8^{\prime}\right)$

$\operatorname{text}\left(29.4,21,{ }^{\prime} \mathrm{fc}=1 '\right)$

\% Plot the Modulating signal alone. Graph 2.

figure

$\mathrm{df}=\left[\begin{array}{ll}0 & 25\end{array}\right] ; \mathrm{fd}=\left[\begin{array}{ll}0 & 0\end{array}\right]$;

$\mathrm{df} 1=[24.324 .3] ; \mathrm{fd} 1=[0 \mathrm{Am}]$;

$\mathrm{df} 2=[27 \mathrm{27}] ; \mathrm{fd} 2=[0 \mathrm{Am}]$;

plot(df,fd,'m--')

hold

$\operatorname{plot}\left(\mathrm{df} 1, \mathrm{fd} 1, \mathrm{,k}-\mathrm{-}^{\prime}\right)$

plot(df2,fd2,'w-')

plot(t,vm1,'b-')

$\%$ Add text, labels and titles to Graph 2

title('Graph 2: The Modulating Signal $(\mathrm{fm}=1 / 8)$.')

$\operatorname{strg} 11=[$ 'Am = ',num2str(Am)];

$\operatorname{text}(24.5, \mathrm{Am} / 2, \operatorname{strg} 11)$

xlabel('time (s)')

ylabel('Volt or Ampere')

$\%$ Plot the Carrier signal alone. Graph 3.

figure $\mathrm{df}=\left[\begin{array}{ll}0 & 25\end{array}\right] ; \mathrm{fd}=\left[\begin{array}{ll}0 & 0] ;\end{array}\right.$

$\mathrm{df} 1=[24.324 .3] ; \mathrm{fd} 1=[0 \mathrm{Ac}]$;

df $2=[27$ 27]; fd2 $=[0 \mathrm{Ac}]$;

plot(df,fd,'m--')

hold

$\operatorname{plot}(\mathrm{df1}, \mathrm{fd} 1, \mathrm{k}-\mathrm{-})$

plot(df2,fd2,'w-')

$\operatorname{plot}\left(\mathrm{t}, \mathrm{vc} 1, \mathrm{r}^{-}\right)$

$\%$ Add text, labels and titles to Graph 3

title('Graph 3: The Carrier Signal $(\mathrm{fc}=1)$.')

$\operatorname{strg} 12=[' \mathrm{Ac}=$ ', num2str(Ac) $]$;

text $(24.5, \mathrm{Ac} / 2, \operatorname{strg} 12)$

text $\left(25.2,0\right.$, 'time $\left.^{(\mathrm{s})}\right)$

xlabel('time (s)')

ylabel('Volt or Ampere')

$\%$ Plot the Ampilude Modulated wave alone. Graph 4.

figure

$\mathrm{df}=\left[\begin{array}{ll}0 & 24.8\end{array}\right] ; \mathrm{fd}=\left[\begin{array}{ll}0 & 0]\end{array}\right]$

$\mathrm{df} 3=[\mathrm{Am}+\mathrm{Ac}+0.005 \mathrm{Am}+\mathrm{Ac}+0.005] ; \mathrm{df} 4=[-\mathrm{Am}-\mathrm{Ac}-0.005$ -

Am-Ac-0.005];

$\mathrm{fd} 3=[\mathrm{Ac} \mathrm{Ac}]$

$\mathrm{fd} 4=[\mathrm{Ac}-\mathrm{Am}$ Ac-Am];

$\mathrm{fd} 5=[-\mathrm{Ac}-\mathrm{Ac}]$

$\mathrm{fd} 6=[-\mathrm{Ac}+\mathrm{Am}-\mathrm{Ac}+\mathrm{Am}]$

$\mathrm{fd} 7=[-\mathrm{Ac}-\mathrm{Am}-\mathrm{Ac}-\mathrm{Am}]$

$\mathrm{fd} 8=[\mathrm{Ac}+\mathrm{Am} \mathrm{Ac}+\mathrm{Am}]$;

df $2=\left[\begin{array}{lll}31 & 31\end{array}\right] ;$ fd2 $=\left[\begin{array}{lll}0 & \mathrm{Ac}\end{array}\right]$

plot(df,fd,'m--')

hold

$\operatorname{plot}\left(\mathrm{df}, \mathrm{fd} 3, \mathrm{Im}^{--}\right)$

$\operatorname{plot}\left(\mathrm{df}, \mathrm{fd} 4, \mathrm{~m}^{---}\right)$

plot(df,fd5,'m--')

plot(df,fd6,'m--')

$\operatorname{plot}\left(\mathrm{df} 2, \mathrm{fd} 2\right.$, 'w-' $^{-}$

plot(df,df3,'w-')

plot(df,df4,'w-')

$\operatorname{plot}\left(\mathrm{df}, \mathrm{fd} 7, \mathrm{Im}^{--')}\right.$

plot(df,fd8,'m--')

$\operatorname{plot}\left(\mathrm{t}, \mathrm{vam} 1, \mathrm{r}^{-}\right)$

plot(t,env11,'b--')

plot(t,env21,'b--')

$\%$ Add text, labels and titles to Graph 4.

title('Graph 4: The Amplitude Modulated Wave.')

xlabel('time (s)')

strg13=['Ac = ',num2str(Ac)];

text(25.2,Ac,strg13)

strg14=['-Ac = ',num2str(-Ac)];

text(25.2,-Ac,strg14)

$\operatorname{strg} 15=[$ 'Ac+Am = ',num2str(Ac+Am) $]$;

text(25.2,Ac+Am,strg15)

$\operatorname{strg} 16=['-A c-A m=$ ',num2str(-Ac-Am) $;$

text(25.2,-Ac-Am,strg16)

strg17=['Ac-Am = ',num2str(Ac-Am)];

text (25.2,Ac-Am, strg17)

$\operatorname{strg} 18=['-A c+A m=$ ',num2str $(-A c+A m)]$;

text(25.2,-Ac+Am, strg18)

ylabel('Volt or Ampere')

if $\mathrm{Am}<1$

$\mathrm{x}=0.2$;

elseif $\mathrm{Am}<2.5$

$\mathrm{x}=0.3$;

elseif $\mathrm{Am}<3.2$

$\mathrm{x}=0.4$;

else 


$$
\mathrm{x}=0.5 \text {; }
$$

end

strg181=['Ac = ',num2str(Ac),'; Am = ',num2str(Am)]; text (28.5, Ac+Am,strg181)

text(28.5,Ac+Am-x,'Maximum Pick - Pick')

$\operatorname{text}\left(28.5, \mathrm{Ac}+\mathrm{Am}-2^{*} \mathrm{x},{ }^{\prime}=\mathrm{A}=(\mathrm{Ac}+\mathrm{Am})-(-\mathrm{Ac}-\mathrm{Am})^{\prime}\right)$

$\operatorname{text}\left(28.5, \mathrm{Ac}+\mathrm{Am}-3^{*} \mathrm{x},{ }^{\prime} \mathrm{A}=2(\mathrm{Ac}+\mathrm{Am})^{\prime}\right)$

$\mathrm{A}=2 *(\mathrm{Ac}+\mathrm{Am})$

strg19=['A = ',num2str(A)];

text $(28.5, A c+A m-4 * x, s t r g 19)$

text $\left(28.5, \mathrm{Ac}+\mathrm{Am}-5^{*} \mathrm{x},{ }^{\prime}\right.$ Minimum Pick - Pick')

text $\left(28.5, \mathrm{Ac}+\mathrm{Am}-6^{*} \mathrm{x},{ }^{\prime}=\mathrm{B}=(\mathrm{Ac}-\mathrm{Am})-(-\mathrm{Ac}+\mathrm{Am})^{\prime}\right)$

$\operatorname{text}\left(28.5, \mathrm{Ac}+\mathrm{Am}-7^{*} \mathrm{x},{ }^{\prime} \mathrm{B}=2(\mathrm{Ac}-\mathrm{Am}){ }^{\prime}\right)$

$\mathrm{B}=2 *(\mathrm{Ac}-\mathrm{Am})$;

$\operatorname{strg} 20=[$ 'B = ',num2str(B)];

text $(28.5, \mathrm{Ac}+\mathrm{Am}-8 * \mathrm{x}, \operatorname{strg} 20)$

text $\left(28.5, \mathrm{Ac}+\mathrm{Am}-9^{*} \mathrm{x}, \mathrm{,}^{\prime}\right.$ Modulation index')

$\operatorname{text}\left(28.5, \mathrm{Ac}+\mathrm{Am}-10 * \mathrm{x},{ }^{\prime}=\mathrm{m}=(\mathrm{A}-\mathrm{B}) /(\mathrm{A}+\mathrm{B})^{\prime}\right)$

$\operatorname{strg} 21=[$ 'm = ',num2str(A-B),'/',num2str(A+B)];

text $(28.5, \mathrm{Ac}+\mathrm{Am}-11 * \mathrm{x}, \operatorname{strg} 21)$

$\operatorname{strg} 22=[$ 'm = ',num2str((A-B) $/(\mathrm{A}+\mathrm{B}))]$;

text $(28.5, \mathrm{Ac}+\mathrm{Am}-12 * \mathrm{x}, \mathrm{strg} 22)$

text $\left(28.5, \mathrm{Ac}+\mathrm{Am}-13 * \mathrm{x},{ }^{\prime}\right.$ Modulation index')

$\operatorname{text}\left(28.5, \mathrm{Ac}+\mathrm{Am}-14 * \mathrm{x},{ }^{\prime}=\mathrm{m}=\mathrm{Am} / \mathrm{Ac}\right.$ ')

strg23=['m = ',num2str(Am),'/',num2str(Ac) $]$;

text $(28.5, \mathrm{Ac}+\mathrm{Am}-15 * \mathrm{x}, \mathrm{strg} 23)$

strg24=['m = ',num2str(Am/Ac)];

text $(28.5, \mathrm{Ac}+\mathrm{Am}-16 * \mathrm{x}, \mathrm{strg} 24)$

$\mathrm{m}=\mathrm{Am} / \mathrm{Ac}$

if $\mathrm{m}>1$

text(28.5,Ac+Am-19*x,'m > 1, Lower Envelope overlaps')

text(28.5,Ac+Am-20*x,'with the Upper Envelope')

text $\left(28.5, \mathrm{Ac}+\mathrm{Am}-21^{*} \mathrm{x},{ }^{\prime} \mathrm{vm}\right.$ is not recoverable from vam') else

text $\left(28.5, \mathrm{Ac}+\mathrm{Am}-19^{*} \mathrm{x},{ }^{\prime} \mathrm{m}<\right.$ or $=1$, No overlapping of $)$

text(28.5,Ac+Am-20*x,'Lower and Upper Envelopes')

text $\left(28.5, \mathrm{Ac}+\mathrm{Am}-21^{*} \mathrm{x}, \mathrm{\prime vm}\right.$ is recoverable from vam') end

$\%$ Plot the Demodulated wave alone. Graph 5.

figure

$\mathrm{df}=\left[\begin{array}{ll}0 & 25\end{array}\right] ; \mathrm{fd}=\left[\begin{array}{ll}0 & 0\end{array}\right] ; \mathrm{fd} 5=\left[\begin{array}{ll}-2 & -2\end{array}\right] ;$

$\mathrm{df} 1=[24.324 .3] ; \mathrm{fd} 1=[0 \mathrm{Am}]$;

df2 $=\left[\begin{array}{ll}27 & 27\end{array}\right] ; \mathrm{fd} 2=[0 \mathrm{Ac}]$;

plot(df,fd,'m--')

hold

$\operatorname{plot}\left(\mathrm{df} 1, \mathrm{fd} 1, \mathrm{,k}-{ }^{\prime}\right)$

$\operatorname{plot}\left(\mathrm{df} 2, \mathrm{fd} 2, \mathrm{w}^{-}\right)$

plot(df,fd5,'k-')

$\operatorname{plot}\left(\mathrm{t}, \mathrm{vd} 1, \mathrm{~b}^{-}\right)$

$\%$ Add text, labels and titles to Graph 5.

title('Graph 5: The Demodulated Wave.')

$\operatorname{strg} 25=[$ 'Am = ',num2str(Am)];

$\operatorname{text}(24.5, \mathrm{Am} / 2, \operatorname{strg} 25)$

text $(25.2,0$, 'time (s)')

xlabel('time (s)')

ylabel('Volt or Ampere')

if $\mathrm{m}>1$

text(24.5,0-0.2,'m > 1, Demodulated wave') text $(24.5,0-0.4$, 'is distorted')

else

text $(24.5,0-0.2, ' \mathrm{~m}<$ or $=1$, Demodulated wave')

text $(24.5,0-0.4$,'is exactly the same as vm') end

\% Full AM, Double Side Band Suppressed Carrier DSBSC and Single Side Band (SSB)

for $\mathrm{k}=1: 3000$

$\operatorname{vDSBSC}(\mathrm{k})=4+\left(\operatorname{Am} * \cos \left(2 * \mathrm{pi}^{*} \mathrm{fm} * \mathrm{t}(\mathrm{k})\right)\right) * \cos (2 * \mathrm{pi} * \mathrm{fc} * \mathrm{t}(\mathrm{k}))$; end

$\%$ Upper envelope

for $\mathrm{k}=1: 3000$

env $1(\mathrm{k})=4+\mathrm{Am} * \cos (2 * \mathrm{pi} * \mathrm{fm} * \mathrm{t}(\mathrm{k}))$;

end

$\%$ Lower envelope

for $\mathrm{k}=1: 3000$

env2 $(\mathrm{k})=4-\mathrm{Am} * \cos (2 * \mathrm{pi} * \mathrm{fm} * \mathrm{t}(\mathrm{k}))$; end

for $\mathrm{k}=1: 3000$

$\operatorname{vSSB}(\mathrm{k})=-5+\mathrm{Am} * \cos (2 * \mathrm{pi} *(\mathrm{fc}-\mathrm{fm}) * \mathrm{t}(\mathrm{k})) / 2$; end

$\%$ Plot the Full AM, the Double Side band Suppressed Carrier (DSBSC) and the

$\%$ Single Side Band (SSB) Waves on the same graph. Graph 6.

$\mathrm{ee}=\left[\begin{array}{ll}16 & 16\end{array}\right]$

ee2=[4 4];

ee $3=[4+\mathrm{Am} 4+\mathrm{Am}]$;

ee $6=[4-\mathrm{Am} 4-\mathrm{Am}]$;

ee9 $=[-5-5]$;

ae $1=[27.65$ 27.65]; ea1=[16+Ac+Am 16-Ac-Am];

eee $3=[16+$ Ac $16+$ Ac $]$;

eee $4=[16+A c+A m 16+A c+A m] ;$

eee $5=[16+$ Ac-Am $16+A c-A m]$

eee $6=[16-A c$ 16-Ac];

eee $7=[16-\mathrm{Ac}+\mathrm{Am} 16-\mathrm{Ac}+\mathrm{Am}]$;

eee $8=[16-A c-A m$ 16-Ac-Am];

eee $1=[-5+\mathrm{Am} / 2-5+\mathrm{Am} / 2]$;

eee $2=[-5-\mathrm{Am} / 2-5-\mathrm{Am} / 2]$;

$\mathrm{ap}=\left[\begin{array}{l}20.5 \\ 20.5\end{array}\right] ; \mathrm{pa}=\left[\begin{array}{ll}31.2 & 33.5\end{array}\right]$;

ddd $1=\left[\begin{array}{ll}0 & 27.6\end{array}\right]$

$\operatorname{ddd} 2=\left[\begin{array}{ll}0 & 24.6\end{array}\right]$

$\mathrm{ae}=[24.6524 .65] ; \mathrm{e}=[16+\mathrm{Ac}-\mathrm{Am} 16-\mathrm{Ac}+\mathrm{Am}]$;

eea $=[4-\mathrm{Am} 4+\mathrm{Am}]$;

eaa $=[-5-A m / 2-5+A m / 2] ;$

figure

plot (dd,ee,'g--')

hold

plot (de,ed,'w--')

plot (dd,ee1,'g--')

plot (dd,ee2,'g--')

plot (ddd2,ee3,'m--')

plot (ddd2,ee6,'m--')

plot (dd,ee9,'g--')

plot (dd,eee3,'m--')

plot (ddd1,eee4,'m--')

plot (ddd2,eee5,'m--')

plot (dd,eee6,'m--')

plot (ddd2,eee7,'m--')

plot (ddd1,eee8,'m--')

plot(t,env12,'b--')

plot(t,env22,'b--')

plot (ae1,ea1,'k-') 


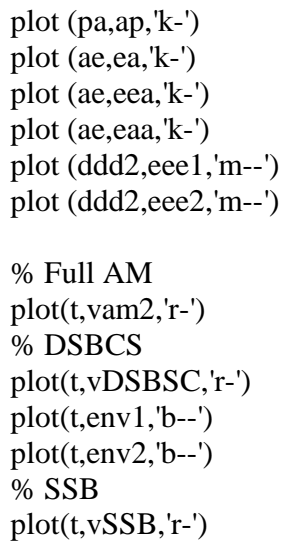

\% Add text, labels and titles to Graph 6

title('Graph 6: the Full AM, the Double Side band Suppressed Carrier (DSBSC) and the Single Side Band (SSB) Waves.') xlabel('time (s)')

ylabel('Volt or Ampere')

text $\left(24.85,16.5,{ }^{\prime 2}(\mathrm{Ac}-\mathrm{Am})^{\prime}\right)$

$\mathrm{B}=2 *(\mathrm{Ac}-\mathrm{Am})$;

$\operatorname{strg} 1=['=\mathrm{B}=$ ',num2str(B)];

text $(24.85,15.3, \operatorname{strg} 1)$

text $\left(27.85,16.5,2(\mathrm{Ac}+\mathrm{Am})^{\prime}\right)$

$\mathrm{A}=2 *(\mathrm{Ac}+\mathrm{Am})$;

$\operatorname{strg} 2=['=\mathrm{A}=$ ',num2str(A)];

$\operatorname{text}(27.85,15.3, \operatorname{strg} 2)$

$\mathrm{m}=\mathrm{Am} / \mathrm{Ac}$

text(1.5,-1.3+14.5-Am,'Full AM: 3 freuency components at $\mathrm{fc}, \mathrm{fc}+\mathrm{fm}$ and $\left.\mathrm{fc}-\mathrm{fm}^{\prime}\right)$

strg5=['m = (',num2str(A), ' - ',num2str(B), ')'];

strg6=[' (',num2str(A), + ',num2str(B),')'];

text(30.4,24.2,'Modulation index')

$\operatorname{text}\left(30.4,22.8, ' \mathrm{~m}=(\mathrm{A}-\mathrm{B}) /(\mathrm{A}+\mathrm{B})^{\prime}\right)$

$\operatorname{text}(30.4,21.4, \operatorname{strg} 5)$

$\operatorname{text}(30.4,19.8, \operatorname{strg} 6)$

$\operatorname{strg} 7=[$ 'm = ',num2str(A-B),'/',num2str(A+B)];

$\operatorname{text}(30.4,18.6, \operatorname{strg} 7)$

$\operatorname{strg} 8=[$ 'm = ',num2str((A-B)/(A+B))];

text $(30.4,17.4, \operatorname{strg} 8)$

$\mathrm{m}=\mathrm{Am} / \mathrm{Ac}$

text(1.5,-1.3+4.5-Am,'Double Side Bands Suppresed Carrier (DSBSC) wave: 2 freuency components at $\mathrm{fc}+\mathrm{fm}$ and $\mathrm{fc}-\mathrm{fm}$ ')

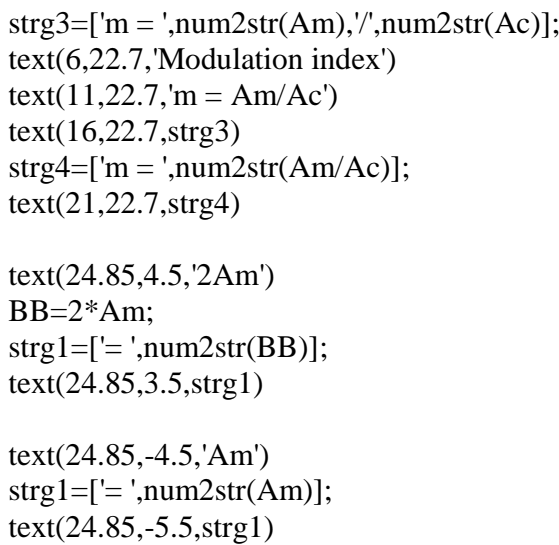

text(1.5,-1.3-3.5-Am,'Single Side Band (SSB) wave: 1 freuency component at fc-fm')

text(26.2,7.1,'Percentage Power-saving by DSBSC') text $\left(26.2,5.0,{ }^{\prime}\right.$ PsavingDSBSC $=200 /\left(2+\mathrm{m}^{*} \mathrm{~m}\right) \%$ ')

$\operatorname{strg} 7=[$ 'PsavingDSBSC $=$

',num2str(200),'/',num2str(2+m*m),'\%'];

text $(26.2,3.2, \operatorname{strg} 7)$

strg8=['PsavingDSBSC = ',num2str(200/(2+m*m)),'\%'];

text $(26.2,1.2, \operatorname{strg} 8)$

text(26.2,-2.7,'Percentage Power-saving by SSB')

text $\left(26.2,-4.8,{ }^{\prime}\right.$ ssavingSSB $=50(4+\mathrm{m} * \mathrm{~m}) /(2+\mathrm{m} * \mathrm{~m}) \%$ ')

strg7=['PsavingSSB =

',num2str(50*(4+m^2)),'/',num2str(2+m*m),'\%'];

text $(26.2,-6.6, \operatorname{strg} 7)$

$\operatorname{strg} 8=\left[\right.$ 'PsavingSSB $=$ ',num2str $\left(50 *\left(4+\mathrm{m}^{\wedge} 2\right) /\left(2+\mathrm{m}^{*} \mathrm{~m}\right)\right),{ }^{\prime} \%$ ']; text $(26.2,-8.6, \operatorname{strg} 8)$

strg9=['Am = ',num2str(Am)];

text $(6,24, \operatorname{strg} 9)$

$\operatorname{strg} 10=[' A c=$ ',num2str(Ac) $]$;

text $(11,24, \operatorname{strg} 10)$

$\operatorname{text}\left(16,24,{ }^{\prime} \mathrm{fm}=1 / 8^{\prime}\right)$

$\operatorname{text}\left(21,24\right.$, 'fc $^{\prime}=1$ ')

$\%$ End 